\title{
TOLL-MANAGED LANES: A SIMPLIFIED BENEFIT- COST ANALYSIS OF SEVEN US PROJECTS
}

\author{
Carter B. Casady ${ }^{1 *}$, José A. Gómez-Ibáñez ${ }^{2}$, and Emily Schwimmer ${ }^{3}$
}

\begin{abstract}
Toll managed lanes are expressway lanes where tolls are used-often in combination with preferred access for high occupancy vehicles and other special traffic management techniques - to improve the highway's capacity, speed or reliability. Such lanes have become popular with transportation policymakers as a way of maintaining free-flowing traffic on certain sections of the highway while also, in some cases, financing the construction of new lanes in congested urban areas. This study examines whether toll-managed lanes are as beneficial as they are popular. The heart of the analysis is the application of a simplified social benefit-cost analysis (BCA) to seven projects. In brief, our results paint a complicated picture of toll-managed lane efficacy. Only two of the seven projects have benefit-cost $(\mathrm{B} / \mathrm{C})$ ratios above 1.0 using our base case assumptions about the value of travel time saved and the discount rate, although three others approach or exceed 1.0 with more optimistic but plausible assumptions. The most successful generate not only a significant savings of around 4 to 5 minutes per trip for motorists who switch to the managed lane but also smaller per-trip savings for the large majority of motorists who continue to use the general-purpose lanes. It is important to acknowledge, however, that these calculations depend upon some uncertain assumptions about the value of travel time savings and improved reliability.
\end{abstract}

\section{KEYWORDS}

Managed lanes; transportation; public-private partnerships (PPPs); tolls; benefit-cost analysis (BCA); value of time (VOT)

\footnotetext{
${ }^{1}$ Postdoctoral Scholar, Civil and Environmental Engineering, Stanford University, USA, 310-592-8163, cbcasady@stanford.edu, *Corresponding author

${ }^{2}$ Professor, Urban Planning and Public Policy, Harvard University, USA, 617-495-1341, jose_gomezibanez@hks.harvard.edu

${ }^{3}$ MS, Urban Planning, Harvard University, emarsh@gsd.harvard.edu
} 


\section{INTRODUCTION}

Toll-managed lanes have become popular with transportation policymakers as a way of squeezing more capacity out of existing expressway lanes and/or financing the construction of new lanes in congested urban areas. These managed lanes usually operate alongside, and as alternatives to, the general-purpose lanes of an expressway and utilize special traffic management techniques to improve traffic capacity, speeds, or reliability (FHWA 2012, 1-4 1-6), such as:

1) Restricting access to vehicles of particular types or occupancies, the most common example being High Occupancy Vehicle (HOV) lanes;

2) Restricting entrances and exits to the lanes, such as special express, contraflow or reversible lanes or through expressway ramp metering; and

3) Requiring users to pay a toll or congestion charge for access to the lanes.

Toll-managed lanes promise to provide a faster option for motorists who are pressed for time and reduce congestion in the general-purpose lanes by diverting traffic to the tolled lanes (Poole and Orski 2000). Ginger Goodin, former Chair of the Transportation Research Board's (TRB) Joint Subcommittee on Managed Lanes (2007-2013), concurs, stating "managed lanes [also] offer an opportunity to preserve a portion of the freeway capacity for a higher level of service" (Obenberger, 2004). To achieve these objectives, these lanes generally take on two distinct forms: (1) those which collect tolls solely to regulate congestion; and (2) those which raise additional revenues needed to finance the construction of the managed lanes or other related highway facilities. Schemes designed to primarily manage congestion tend to be conversions of existing and underutilized HOV lanes into High Occupancy Toll (HOT) lanes. These HOT lanes restrict access to both motorists willing to pay a toll and high occupancy vehicles, such as carpools or buses, who are allowed to use the lane for free or at a discount off the normal toll. Conversely, schemes designed to raise revenue as well as combat congestion usually take the form of newly-constructed HOT lanes, Value Pricing Lanes, or Express Toll Lanes (ETLs) which do not typically allow high-occupancy vehicles discounted or free access to the lanes (Collier and Goodin 2004; Poole 2014). Because these purpose-built managed lanes tend to be very expensive, requiring investments of billions of dollars, they are often delivered through public-private partnerships (PPPs) in which private investors are awarded a concession to build the managed lanes and then operate them for a fixed term, usually of 30 to 50 years (FHWA 2016).

Although variants of toll-managed lanes have been around for decades, the introduction of HOT lanes in the early 1990s generated renewed interest in managed lanes as a less controversial means of introducing tolling on roads to manage congestion. The pioneer was the State Route (SR) 91 Express Lanes, a pair of lanes serving commuters who lived in Riverside County and worked in Orange County, California. The ten-mile facility was built alongside and within the right of way of the SR-91 freeway by private investors who had won a contract from the State of California for a concession to build and operate the lanes for 35 years. The concession was the result of state legislation that enabled California's transportation agency to contract with private entities to build expressways and collect tolls from the motorists using them. The SR-91 lanes cost only $\$ 125$ million to build and generated as much as $\$ 40$ million in revenue per year at their peak, just before the investors were bought out by Orange County when it wanted to add more lanes to the expressway. ${ }^{4}$ In the first ten years after the opening of

\footnotetext{
${ }^{4}$ Adding lanes was prohibited under the original contract in an effort to limit the amount of competition the entity would face.
} 
SR-91, only two additional managed lane projects were deployed in the United States. However, by 2010 the number of managed lane corridors in operation increased to nine. By 2018, this number ballooned to 48, with many more under construction (see, e.g. Swimmer, Gómez-Ibáñez, and Casady 2019).

Although toll-managed lanes have risen in popularity across the United States, the benefits associated with these projects remain understudied. While many scholars view HOT lanes as "a better way to attack urban highway congestion" (Poole and Orski 2000, 15), ex-post evaluations of these projects are rare. Collier and Goodin $(2004,1)$ offer "a cross-cutting study of the issues and experiences of various agencies as managed lane projects are implemented and policies are drafted" but fail to examine their relative costs and benefits. Likewise, Obenberger (2004) indicates "[ $\mathrm{t}$ ]ransportation agency experience is beginning to show that managed lanes help control demand; improve the safety, mobility, and performance of freeways and transit systems; and offer travel options that save time and enhance the reliability of travel times" but provides no empirical evidence to support this claim. In recent years, other scholars (see, e.g. Burris and Patil 2009; Devarasetty, Burris, and Shaw 2012; Patil, Burris, Shaw, and Concas 2011) have scrutinized the value of travel times savings (VTTS) associated with managed lanes. However, many of these extant studies stop short of conducting benefitcost analyses (BCAs) for these projects as well.

Nevertheless, some scholars and government agencies have attempted to quantify the costs and benefits of a handful of managed lane projects in the past (see, e.g. Burris and Sullivan 2006; Sullivan and Burris 2006; Buckeye 2012; Alameda County Transportation Commission 2013; USDOT 2013; Buckeye 2014; USDOT 2014a; USDOT 2014b; FHWA 2015). For example, Sullivan and Burris $(2006,191)$ "found that the incremental societal benefits of the SR-91 Express Lanes exceeded costs for the time period considered." A companion paper by Burris and Sullivan (2006) also found similar results for the QuickRide program using the same methodology. However, the impact of each of these projects was dramatically different. Although the projects had similar benefit-cost $(\mathrm{B} / \mathrm{C})$ ratios (1.5 and 1.7 respectively), tens of thousands of travelers were impacted daily on SR 91 while QuickRide's impact was limited to approximately 400 travelers per day. Conversely, FHWA (2015, x) BCAs for five congestion pricing demonstrations sites found "[t]he results were modest, or in some cases negative, perhaps reflecting the experimental nature of some of the investments. In addition, limitations in data available to measure some benefits at certain sites may have impacted the findings." As a whole, many of these published BCAs are also hard to compare because they vary in the costs and benefits they include as well as the ways these benefits and costs are estimated. ${ }^{5}$

In light of these challenges, this paper builds off the extant BCAs and examines whether toll-managed lanes are as beneficial as they are popular. The heart of the analysis is the application of a simplified social benefit-cost analysis (BCA) to seven projects. Using detailed data on travel volumes, speeds, and tolls by time of day and lane, we focus on the primary benefit of travel time savings and reliability improvements enjoyed by users of the managed lanes. We also employ a uniform set of assumptions in our assessment of B/C ratios across a variety of different managed lane types. In the following section, we begin by briefly summarizing some of the challenges associated with toll-managed lanes. Next, we outline the case types and assumptions used in out simplified BCA methodology. Then, we report our results and sensitivity analyses, followed by a short discussion of our findings. Finally, we

\footnotetext{
5 An exception is FHWA (2015) which compared six congestion pricing demonstrations in six metropolitan areas and included benefit-cost analyses for five sites. We included four of the sites among our seven (Atlanta, Los Angeles, Minneapolis and Seattle) because the more detailed reports on the individual metropolitan areas included good before and after data on speeds and volumes. We performed our own benefit-cost analyses, however, to be sure that the assumptions and methodologies were reasonable and consistent across cities.
} 
conclude with our overall takeaways of the study, lingering research limitations, and considerations for future toll-managed lane assessments.

\section{CHALLENGES OF TOLL-MANAGED LANES}

Although debates about toll road efficiency have persisted for decades (see, e.g. Beckmann, 1967; Wilson, 1983; d'Ouville and McDonald, 1990, etc.), economists generally agree that "[t]olls are economically optimal if they induce an efficient use of the available road capacity" (Beckman 1967, 331). However, achieving optimal capacity is not so simple. In many cases, "[a] toll on only one of several roads is less efficient and should be smaller than in the case where tolls are charged on many or all parallel facilities" (Beckman 1967, 331). Wilson (1983, 337) also points out that a:

pricing constraint lowers the optimal capacity, if the price elasticity is sufficiently high. But under reasonable assumptions, the pricing constraint raises the optimal capacity, if the price elasticity is less than the ratio of the consumer price of travel to the private congestion cost at the second-best optimum.

d'Ouville and McDonald (1990, 34) further show that second-best vs. first-best capacity often depends on the "demand" and "cost" effects of congestion tolls while Ferrari $(2002,471)$ suggests that "optimum tolls are independent of the fixed costs of the road sections on which they are imposed, whereas they depend heavily on the marginal costs of public funds and the willingness of motorists to pay." Taken together, these extant studies illustrate toll road efficiency is inextricably linked to the willingness to pay of motorists as well as the availability of viable alternative, toll-free routes.

These factors also make the design of efficient toll-managed lane systems especially challenging because "travelers choose between two adjacent roadways, one free but congested, the other priced but free-flowing" (Small and Yan 2001, 311). Offering "priced options additional to existing congested toll-free roads" (Starkie 1986, 169) is often referred to as "value pricing." In these programs, Small and Yan $(2001,311)$ note there are several possible strategies for setting the tolls in these systems. For example:

One is to apply the "second-best" toll to the express roadway, chosen to maximize social welfare subject to the zero-toll constraint on the other roadway. Another is to apply a "profit-maximizing" toll which maximizes revenue, subject to the same constraint. A third is to set the toll just high enough to keep it flowing at a minimum specified speed.

In any of these scenarios, the efficiency and overall efficacy of toll-managed lanes depends on their relative attractiveness to the free parallel general-purpose lanes. However, the very presence of free parallel general-purpose lanes makes revenues more volatile than they would be on a conventional toll road in which all lanes are tolled. Additionally, because managed lanes tend to be more attractive when the general-purpose lanes are congested, there will be more traffic in the general-purpose lanes and less in the managed lanes than the social optimum. Likewise, the managed lane must generate the majority of its revenue during only a half-dozen hours of the day when traffic peaks. Together, these factors make it harder to ensure that social benefits exceed social costs and revenues exceed financial costs (Fitch 2013, 2017; Moody's Investor Service 2013). Thus, tolling only a subset of the lanes is an inherently inferior strategy for maximizing social welfare and ensuring financial viability compared to tolling all lanes.

This inferiority is compounded by the fact that managed lanes are often used when traffic volumes are close to a highway's capacity. In these circumstances, speeds are very sensitive to 
fluctuations in volumes (Regan 2009). This makes it harder and more important for the managed lane operator to estimate in advance what the optimal toll should be and strengthens the case for using dynamic pricing in which the toll is adjusted frequently in response to realtime changes in traffic volumes and speeds.

To complicate matters further, many states give away some of the HOT lane capacity for free or at a discount. In particular, many HOT lanes allow carpools of three or even two persons to travel for free while California also exempts zero emissions vehicles from tolls as well. These discounts might be justified by the environmental benefits generated from carpooling and cleaner vehicles. It is doubtful, however, that the discounts induce significant increases in carpooling or the purchase of clean cars unless congestion is particularly high. Further, these discounts potentially displace motorists that value the capacity more (Poole 2017).

Finally, political constraints sometimes limit pricing. HOT lanes can be victims of their own success if toll rates needed to control congestion increase rapidly and these increases must be approved by public officials. For example, I-95 in Florida, which is one of our case studies, saw peak tolls needed to achieve reasonably free-flowing traffic increase from $\$ 2$ per car in August 2012, shortly after its HOT lane opened, to $\$ 10$ per car by March 2017. Tolls must be allowed to increase with congestion if the managed lanes are to remain free-flowing. Managed lane projects that are PPP's typically include provisions in their contracts that protect their right to, or even oblige them to, raise tolls as needed to maintain free-flowing speeds in the managed lanes. Absent such protections, public officials might reduce the benefits of managed lane schemes by holding down tolls. High tolls may be economically advantageous in highly congested situations, but they are seldom popular politically (Regan 2017).

\section{SIMPLIFIED BENEFIT-COST ANALYSES: CASES TYPES AND ASSUMPTIONS}

\subsection{Case Types: Conversions, NeW Lanes, AND RebuildS}

The seven cases analyzed in this study were selected to represent three types of toll-managed lanes: conversions, new lanes, and rebuilds.

\subsubsection{Conversions}

The most common type of toll-managed lane project is designed to increase the utilization of existing HOV lanes by opening them to toll-paying SOVs. ${ }^{6}$ The primary concern in toll setting is to ensure that the managed lane is not congested rather than to raise revenue to offset the costs. Typically, conversions are implemented by public agencies rather than through publicprivate partnerships (PPPs) because the cost to convert 10-15 miles of lanes is often less than $\$ 100$ million, which is not enough to justify the transactions costs associated with a partnership.

One of our cases - the I-680 Southbound Express Lane - opened in September 2011 as the first conversion of an HOV lane to a HOT lane in Northern California. It was part of a demonstration program funded in part by the State of California so its experience has been carefully documented by the primary implementing agency, the Alameda County Transportation Commission (2013). Converted at a cost of only $\$ 36.6$ million, the lane runs south 14 miles along I-680 from the intersection with SR-84 in Alameda County to the intersection with SR-237 in Santa Clara County. Access to the original HOV lane was limited to HOV2+ and vehicles that had been certified as low emissions or electric powered. These vehicle types are exempt from tolls in the new HOT lane. While the time savings on the lane were not very impressive, they were enough to convince Alameda County to move forward with the design of a parallel northbound project.

\footnotetext{
${ }^{6}$ Conversions generally don't attract the interest of private companies because they have too little space to sell and too many hassles (i.e. dealing with carpools). As a result, many of these lanes are often owned and operated by government agencies (see Appendix A in Schwimmer, Gomez-Ibanez, and Casady, 2019).
} 
Our case studies also include one of the earliest and most influential conversions: Phase One of the Florida's 95 Express lanes. The project, which opened in two sub-phases in 2008 and 2010, involved the replacement of one HOV lane with two HOT lanes on a 7.2-mile section of I-95 stretching north from Miami. The existing four general purpose lanes were retained and a second managed lane created simply by restriping the roadway to make traffic lanes and shoulders a bit narrower. The cost, including toll collection and enforcement equipment, was only $\$ 139$ million, and the effect on traffic speeds in this congested corridor was dramatic. Phase Two of the 95 Express Lanes was completed in 2016, which extended the express lanes to 22 miles, and Phase Three is currently underway.

At the other extreme is the case of the I-85 Express Lanes in Georgia, which performed poorly when the facility opened in October 2011. At a cost of \$61 million, that project involved the conversion of a 16-mile stretch of HOV lanes on I-85W north of Atlanta to HOT lanes. When the standard for HOVs exempt from tolls was tightened from $\mathrm{HOV} 2+$ to HOV3+, the lanes experienced disappointing usage. This ultimately led state officials to expand Atlanta's planned managed lane network by building new managed lanes rather than converting existing lanes (FHWA 2015, 42).

\subsubsection{New Lanes}

The second type of project involves the construction of new toll-managed lanes alongside the existing general-purpose lanes. In these cases, tolls are usually set both to manage congestion and to finance all or most of the cost of building the new lanes, which can be as high as several hundred million dollars. SR-91 in California is the pioneering and best-known example of new lane construction.

None of our case studies involves new lanes alone. New toll-managed lanes are usually built in conjunction with conversions of HOV lanes or with the rebuilding of existing generalpurpose lanes. One of our case studies, I-405 in Seattle, Washington involves the conversion of 17 miles of HOV lanes between Bellevue and Lynnwood, as well as the construction of a second HOT lane from Bellevue to Bothell. The project is part of a 2010 plan to build a 40plus mile system of HOT lanes to serve the Eastside Corridor - second only to I-5 as the most congested north-south artery in the Seattle metropolitan area (WSDOT 2010). The project began construction in 2012 and opened in September 2015.

Another of our cases, I-35W in Minnesota, involves a complex mixture of converting HOV to HOT lanes, constructing new purpose-built HOT lanes and rebuilding an existing expressway while adding HOT lanes (Buckeye 2012, 2014). The I-35W lanes connect the southern suburbs with downtown Minneapolis. The first six miles consists of one HOV lane in each direction that was converted to a HOT lane (still allowing HOV2+). The next 8 miles is an existing three-lane expressway called Crosstown Commons that was rebuilt to add both a general-purpose lane and a HOT lane in each direction. The third and final 2-mile section involves the conversion of a north-bound shoulder lane that had been open to HOV's in the peak period to a HOT lane that Minnesota officials christened the Priced Dynamically Shoulder Lane, or PDSL for short. The conversion of the southern HOV lanes and the northern PDSL lanes to HOT lanes cost only $\$ 40$ million but the reconstruction of Crosstown Commons cost \$228 million (USDOT 2013, J-5).

\subsubsection{Rebuilds}

Finally, the most ambitious projects involve the construction of additional managed lanes in conjunction with the rebuilding of the existing general-purpose lanes. The rebuilding may be required to fit the added lanes within a relatively narrow existing right-of-way or because the basic roadway and structures are reaching the end of their lives. But the rebuilding also offers the possibility of better integrating the managed lanes with the general-purpose lanes by, for example, connecting expressways through high-speed ramps or other measures. Rebuilding 
projects typically cost $\$ 1$ to $\$ 3$ billion, sums large enough to make it attractive to incur the transaction costs of procuring the facilities through a public-private partnership. The scale of these projects stems from the fact that most are part of a larger regional plan for a network of managed and improved general-purpose lanes. The Federal Highway Administration (2012, 18) lists Seattle, Austin, Salt Lake City, San Diego, Houston, Dallas-Fort Worth, Miami and Northern Virginia as incorporating managed lanes in major highway expansion program. Early influential examples include the Katy Expressway in Houston Texas and the I-95/I-495 express lanes in Virginia; the former is a publicly-managed project while the latter is a public-private partnership.

Among our case studies, the middle third of I-35W in Minnesota (the Crosstown Commons) is essentially a rebuild project but the larger scale examples are the LBJ and North Tarrant expressways in Texas. These two expressways are part of a larger project to build an extensive network of toll-managed lanes in the Dallas-Fort Worth metropolitan area. Some segments are being built by public agencies while others, including the LBJ and North Tarrant, are being built by private concessionaires as public-private partnerships. The 13.3-mile North Tarrant Expressway project, completed in late 2014 at a cost of $\$ 2.1$ billion, involves the construction of two new managed lanes and the rebuilding of two to three existing general-purpose lanes and two frontage roads lanes in each direction. Also 13.3 miles long and completed in late 2015 at a cost of $\$ 2.6$ billion, the LBJ Expressway consists of a 3.6-mile segment with two-to-three new managed lanes in each direction and a 9.7-mile segment with two-to-three new managed lanes, four rebuilt general-purpose lanes and two new frontage road lanes in each direction.

\subsection{AsSumptions For Simplified Social BenEFit-Cost ANALysis}

\subsubsection{Before and After Timeframe}

With a few exceptions, we estimate the benefits and costs of managed lanes by comparing data on the performance of the lanes the year before and the year after they opened for service. The short timeframe is used in an effort to control for other factors that may influence the utilization of the highway in the longest term, such as the onset of an economic recession or recovery and the improvement of a parallel or feeder road.

A key drawback of the short timeframe is that it is likely to underestimate the net benefits of the managed lanes when traffic increases rapidly after the first year. The underestimate may be modest, however, since the increase in the number of motorists enjoying higher speeds would be offset at least in part by the reduction in speeds caused by the added traffic. Moreover, managed lanes are typically proposed for heavily congested highways that serve already built up areas of the metropolis. Therefore, the potential for sustained rapid growth is more modest than it would be for a less congested highway serving a "greenfield" area that is underdeveloped but ripe for build out. In the former situation, most residents presumably respond to the new lanes by deciding whether or not to use the lanes for their current commute rather than by making more fundamental and long-term choices about where to work or live. Nevertheless, several of our cases, including two highways in Dallas, have experienced sustained and rapid traffic growth. Our short time frame of analysis likely fails to capture their continued ramp up in traffic, almost certainly resulting in the underestimation of their net benefits.

\subsubsection{Travel Times by Time Period and Segment}

Travel times are estimated using speed and volume data from the agency that supervises the managed lanes. Time savings are assumed to occur only during the morning and evening peak periods on weekdays. The specific hours used are typically the two three-hour periods which the supervising agency defines as its peaks. We assume 250 weekdays in a year.

It is critical that the speed and volume data are for the same time periods and highway segments. Segment-specific speed and volume data are used where they are available. If 
average speed and volume figures are available only for the entire facility, then we assume that managed lane users travel the entire length of the lane, an assumption which almost surely exaggerates the effects of the lanes.

\subsubsection{Minutes of Travel Time Saved}

The principal benefit of the managed lanes is the minutes of travel time the motorists save. Conversely, any increase in travel time is a cost. If motorists used the highway before the tollmanaged lanes were opened and continue to do so, then their savings is simply the difference between their travel time before and after the managed lanes become operational. If motorists did not use the highway before but use either the general purpose or managed lanes after, then we follow the conventional practice of estimating their savings as one-half the difference between the time they would have spent had they used the road before and the time they spend now. The reasoning is that the decision of motorists not to use the road before indicates that they value the trip at less than the travel time before while their decision to use the road after indicates that they value the trip by at least the travel time after. If the time before is the upper bound and the time after is the lower bound, then one-half the difference is a reasonable approximation.

Another simplification is that we do not calculate the time savings or losses separately for HOV users but rather treat all toll-managed lane users as if they were toll paying singleoccupant vehicles (SOVs). We make this assumption because we do not have data on the mix of SOVs and HOVs in the managed lanes for several of our cases. Moreover, the assumption causes no problems in projects that involve the construction of managed lanes where there were none before. In projects where HOVs had been allowed to use managed lanes before but not afterward, however, the assumption typically overstates the benefits since the speeds in the managed lanes are typically faster than the speeds in the general-purpose lanes the HOVs now must use.

Another complication, particularly for projects involving new lanes rather than conversions, is that we have no data on how many of the new managed lane users are former users of the general-purpose lanes and how many are new users of the road. The usual assumption is that they are new users to the road and thus benefit by one-half the difference between the travel times on the general-purpose lanes before and the managed lanes after. But, if one assumes instead that they are former users of the general-purpose lanes, then they benefit by the full difference between general-purpose time before and managed lane time after rather than by half the difference. We adopt the latter assumption since it seems likely that the managed lanes would draw more from existing road users than those who had not made the trip before. This assumption, however, significantly increases the benefits of projects that generate a big increase in managed lane use.

\subsubsection{The Dollar Value of Travel Time Savings}

Since reduced travel time is one of the principal benefits of managed lanes, the dollar value travelers place on travel time saved is obviously a critical assumption in our social BCA. There is an extensive body of empirical research that suggests that commuters' value travel time savings at 35 to 60 percent of their wage rate with a median estimate of about 50 percent (USDOT 2014a, 10-13 and Table 2). This would imply a value of $\$ 12.50$ per hour for a typical managed lane user with an annual income of $\$ 50,000$ working 2000 hours per year. $^{7}$

To translate estimates of time value per traveler hour to time value per vehicle hour we need to make assumptions about average vehicle occupancy as well. The U.S. Census reports an average of 1.1 commuters per automobile. Assuming an overall average vehicle occupancy of 1.2 for all types of trips and an hourly wage of $\$ 12.50$, implies an average value per vehicle

\footnotetext{
${ }^{7}$ A study of Georgia's I-85W Express Lanes reported average household incomes of $\$ 54,000$ in 2011 (USDOT 2014a: L-6)
} 
hour of $\$ 15$. If 9 percent of the traffic were trucks, which have a value of time (VOT) of $\$ 40$ per hour, then the overall value is $\$ 17$ per vehicle hour. This VOT, which we use as our base case, compares reasonably well with the VOT savings guidelines of the US Department of Transportation (2014).

We also assume that travelers using the toll-managed and the general-purpose lanes place the same value on travel time saved when it is likely that the users of the toll-managed lanes value time savings more highly. Small and Yan $(2001,324)$ demonstrated how important the heterogeneity of motorist preferences might be by simulating motorists' behavior in a hypothetical managed lane modeled after California's SR-91. They estimated that the benefits gained by the sorting of motorists across traffic lanes by VOT can offset as much as a third of the inefficiencies of applying tolls on only the managed lanes.

The operators of the North Tarrant Express in Texas argue that the patterns of use of their managed lanes suggest that preferences are very varied. The top 10 percent of the subscribers are regular users who take 10 or more trips per month and account for 55 percent of trips. The bottom 50 percent of subscribers take an average of only 1 trip a month and account for only 13 percent of trips and presumably include many who use the Express Lanes only when the speed and reliability are particularly important. If true, ignoring user heterogeneity will understate the benefits of managed lanes even if the VOT savings is correctly estimated. However, in recent years, Burris and $\operatorname{Brady}(2018,23)$ have also shown that most travellers use the same lane regardless of travel time and toll and "[t]ravelers that used both sets of lanes often made choices that appeared counter-intuitive based on travel time savings and toll rate."

\subsubsection{Value of Increased Reliability}

Many operators and researchers of managed lanes suspect that the benefits from improved reliability are as important as the benefits from reduced travel times. Unfortunately, most agencies with managed lanes do not collect or report reliability data and there is little consensus among transportation researchers as to the appropriate measure of reliability to use or the value to place on reliability gains (USDOT 2014b, 3)

Reliability benefits are likely to be particularly large when new HOT lanes are added alongside expressways that are operating so close to capacity that small changes in traffic volumes cause large changes in speeds. One sign that reliability benefits may be large comes from surveys of the motorists using the managed lanes on the North Tarrant and LBJ expressways which show that they systematically overestimate the savings in travel time they enjoy. Users of the HOT lanes on the North Tarrant Express overestimate the savings by a factor of two, for example, reporting an average of 9.5 minutes saved when the actual savings was 4.4 minutes (Sanchez 2016).

Another sign that reliability is important comes from estimates of the minimum values of travel time saved that are implicit in the decisions by motorists to use HOT lanes. In the cases we studied, these implicit measures of the VOT are typically much higher than the $\$ 17$ per hour suggested by conventional estimates. The implicit values are estimated by simply dividing the tolls paid by SOVs using the managed lanes by the minutes saved and are minimums in that some SOV users presumably would be willing to pay more than the toll charged. The resulting values, shown in Table 1, vary from $\$ 6.47$ to $\$ 82.47$ with no obvious relation to the type of project or its $\mathrm{B} / \mathrm{C}$ ratio (calculated using $\$ 17$ per hour).

Table 1: Implicit Value of Time (VOT) in Decisions of Motorists

\begin{tabular}{lccc}
\hline Case & $\begin{array}{c}\text { Implicit Value of Time } \\
(\$ / \text { hour })\end{array}$ & Type & $\begin{array}{c}\text { B/C ratio } \\
(\text { at } \$ 17 / \text { hour })\end{array}$ \\
\hline Florida I-95 phase 1 & $\$ 6.47$ & Conversion & 3.96
\end{tabular}




\begin{tabular}{lccc} 
California I-680 south & $\$ 65.34$ & Conversion & 0.23 \\
Georgia I-85 & n.a. & Conversion & -0.56 \\
Washington I-405 & $\$ 15.31$ & Conversion and new & 0.29 \\
Minnesota I-35W & $\$ 79.57$ & Conversion and rebuild & 1.32 \\
Texas LBJ & $\$ 77.94$ & Rebuild & 0.03 \\
Texas North Tarrant & $\$ 82.47$ & Rebuild & 0.24 \\
\hline
\end{tabular}

Sources: Authors' calculations based on data from Florida Department of Transportation (2010a; 2010b, tables 3.2 and 3.3; 2011, section 3.3;); Alameda County Transportation Commission (2013, tables 6, 44 and appendix 9.5 tables 60-69); Washington State Department of Transportation (2013; 2016a; 2016b); US Department of Transportation (2013, tables A-6, A-7, A-23 and A-24); and unpublished data supplied by Cintra US.

Given the uncertainty about the value of travel time and reliability, we test the sensitivity of our $\mathrm{B} / \mathrm{C}$ ratios using three assumptions:

1) The base case is $\$ 17$ per hour, a figure consistent with current research on the value of commute time as well as federal agency guidance (see, e.g. FHWA 2015).

2) The second case is $\$ 34$ per hour and assumes that the value of improved reliability is comparable to the value of reduced travel times on highways that are candidates for HOV lanes. An equal weight is justified because the most careful study of the value motorists place on reliability (based on an analysis of the choices of SR-91 users) reports that the value per hour of improved reliability is comparable to the value per hour of travel time savings. ${ }^{8}$ An equal weight is also consistent with surveys showing that managed lane users in Texas overestimate the time savings by a factor of two.

3) The final case is $\$ 70$ per hour and is justified as consistent with the evidence that the VOT varies considerably and is higher among managed lane users. Seventy dollars is also consistent with the higher implicit values of time reported in Table 1.

\subsubsection{The Role of Toll Revenues}

Tolls are considered neither a benefit nor a cost in BCAs of highways but rather a transfer from the motorists who pay them to the agencies that collect and use them. Tolls reflect benefits, however, in as much as a motorist using a tolled facility must enjoy enough benefits to make it worth his or her while to pay the toll. But, if those benefits take the form of savings in time or reliability, then including both tolls collected and travel time saved in the analysis would double-count the benefits motorists enjoy. Because the willingness to pay tolls reflects time savings, however, toll revenues can provide a check on the accuracy of the other benefit estimates. In particular, the estimated value of the time and reliability savings should be greater than the toll revenues collected.

Our estimates of time savings benefits do reasonably well by this standard, but cast further doubt that the VOT savings is as low as $\$ 17$ per hour. A VOT of $\$ 70$ per hour gives the best results, which is not surprising given that the implicit VOT is around that level for many of our cases. As Table 2 shows, at $\$ 70$, the estimated benefits to managed lane users exceed toll revenues in four of the six cases for which we have the needed data and are very close on the remaining two. At $\$ 17$ per hour, however, estimated benefits on managed lanes exceed tolls charged in only two of six cases: Florida's I-95 and Washington's I-405 Express Lanes. Florida in particular charges very low tolls relative to the estimated value of the services provided. But if $\$ 17$ per hour is correct then the users of managed lanes on the other four facilities are irrational in that they are paying more than they benefit in time savings.

\footnotetext{
${ }^{8}$ Small et al. $(2005,1378)$ estimate that users of SR-91 in California value savings in travel times and reliability both at around $\$ 20$ per hour where reliability is measured by the extra commuting time the traveler endures to make sure that he doesn't arrive 10 minutes or more early or late. The reliability savings are about half of the travel time savings on SR-91, so that reliability is about one-third of total travel and reliability savings.
} 


\subsubsection{Excluded Benefits}

Several other benefits of managed lanes are left out of our simplified BCA, either for lack of consistent data or because they are more modest and offsetting to some degree. Many managed lane systems are used by public transit buses as well as private cars. The benefits to transit users are ignored, however, because transit riders are usually greatly outnumbered by the motorists. To be consistent, costs of any transit facilities, vehicles or operations are also excluded.

Table 2: Comparison of Toll Revenues with Estimated User Time Savings

\begin{tabular}{|c|c|c|c|c|c|c|}
\hline \multirow[b]{2}{*}{ Case } & \multicolumn{3}{|c|}{ Toll revenues } & \multicolumn{3}{|c|}{$\begin{array}{l}\text { VOT saved per year in managed lanes in } \\
\text { peak }(\$ 000)\end{array}$} \\
\hline & $\begin{array}{c}\text { Toll } \\
\text { /vehicle }\end{array}$ & $\begin{array}{l}\text { Vehicles/day } \\
\text { in peak }\end{array}$ & $\begin{array}{c}\text { Tolls/year } \\
\text { peak }(\$ 000)\end{array}$ & $\begin{array}{c}\text { At } \\
\$ 17 / \text { hour }\end{array}$ & At $\$ 34 /$ hour & $\begin{array}{c}\text { At } \\
\$ 70 / \text { hour }\end{array}$ \\
\hline Florida I-95 phase 1 & $\$ 1.80$ & 14,880 & $\$ 6,712$ & $\$ 59,075$ & $\$ 118,150$ & $\$ 276,376$ \\
\hline $\begin{array}{c}\text { California I-680 SB } \\
\text { Georgia I-85 }\end{array}$ & $\begin{array}{l}\$ 3.09 \\
\text { n.a. }\end{array}$ & 1,275 & $\$ 985$ & $\$ 256$ & $\$ 512$ & $\$ 1,055$ \\
\hline Washington I-405 & $\$ 2.40$ & 11,097 & $\$ 6,658$ & $\$ 7,355$ & $\$ 14,709$ & $\$ 30,283$ \\
\hline Minnesota I-35W & $\$ 1.19$ & 12,117 & $\$ 3,605$ & $\$ 770$ & $\$ 1,540$ & $\$ 3,171$ \\
\hline Texas LBJ & & & $\$ 32,391$ & $\$ 7,065$ & $\$ 14,130$ & $\$ 29,012$ \\
\hline Texas North Tarrant & & & $\$ 37,638$ & $\$ 29,147$ & $\$ 58,294$ & $\$ 102,018$ \\
\hline
\end{tabular}

Sources: See sources for Table 1.

Additionally, safety may be affected as well. However, it is unclear whether on net it is likely to be improved (perhaps because of the reduction in stop-and-go traffic) or reduced (perhaps because of weaving across the general-purpose lanes to access or exit the managed lanes). A study of Minnesota's I-35W managed lanes was an outlier in reporting 9.4 percent fewer fatal and injury crashes and 25.6 percent fewer property damage crashes in the first six months of operation. Assuming the savings were sustained, the dollar value of the safety benefits were estimated to be roughly two and half times the value of the user time savings. However, the authors of the Minnesota study acknowledged that six months was a short time to identify changes in rates for relatively rare events like traffic fatalities and recommended that the safety record be monitored further (USDOT 2013, 5-23, 5-24 and J-16).

Whether to expect vehicle operating costs and emissions to decline or not is also unclear since they may fall with the reduction of stop-and-go traffic or increase if the managed lanes encourage more travel. But, where the benefits are estimated, they are relatively small. In the I-35W study, for example, the savings in fuel and emissions were only four percent of the user travel time savings (USDOT 2013, J-16).

\subsubsection{Construction and Operating Costs}

For construction and operating costs, our data are drawn from the implementing agency. In several cases the managed lanes were part of a large program to control congestion including other measures such as improvements to public transit. An effort was made to exclude the costs of these other measures.

The most difficult and important cost allocation issues arise with projects that involve the rebuilding of general-purpose lanes as well as the construction of new managed lanes, such as I-35W in Minneapolis and the LBJ and North Tarrant expressways in Dallas-Fort Worth. In all three cases, the original expressways were reportedly reaching the end of their lives and would have had to be rebuilt soon. One could argue that in such cases the managed lanes should not be charged with the cost of rebuilding the original general-purpose lanes, or, at most, should only be responsible for the costs of rebuilding the lanes a little earlier than they would have been otherwise. This issue is further complicated by the fact that the original lanes were rebuilt 
with design standards that were updated and improved to the point where the operator of the Texas projects claims that each lane can carry 20 percent more throughput in the peak period (Sanchez 2016, slide 12). If so, then part of the time savings observed should be attributed to the rebuilding of the original lanes rather than the construction of the managed lanes. Moreover, if the costs of rebuilding are included, one should include the benefits of rebuilding as well, and these benefits must be enormous since the closure of these expressways would presumably create gridlock in the corridors they serve.

There is no easy answer to this cost and benefit allocation problem. To cope with this issue, we report the results of two sets of assumptions. The base case attempts to separate the rebuilding from the managed lanes by charging the managed lanes with only 40 percent of the construction costs, roughly the proportion of managed to total lane miles on the two Texas projects. The alternative assumes that the general-purpose lanes would not have to be rebuilt were it not for the desire to fit new managed lanes in the right of way and thus charges the costs of both building the new managed lanes and rebuilding the existing general-purpose lanes to the project.

\subsubsection{Asset Life and Discounting}

Finally, to simplify matters, we assume that all assets have a life of 30 years, a compromise figure which is very high for toll collection equipment, a little high for pavement and very low for structures and base.

Costs and benefits are discounted at a rate of seven percent per year in real terms, the discount rate recommended by the U.S. Office of Management and Budget. Discount rates of three percent are also tested in our sensitivity analyses. Costs and benefits are presented both as present values for the 30-year life of the managed lanes and as amortized annual values for a typical year during the 30-year life.

In sum, the key uncertainties in our simplified BCA are the hours of travel time saved and the value to place on each hour. We likely underestimate the hours saved by assuming that all savings occur during the weekday peak periods and that there is no traffic ramp up after the first year. But, as we shall see, when we relax those assumptions, the $\mathrm{B} / \mathrm{C}$ ratios do not change greatly. Additionally, we likely underestimate the value of hours saved by using a base case of $\$ 17$ per hour, a figure which ignores reliability benefits and the heterogeneity of users. However, when we relax this assumption as well, there is a more serious impact on our results.

\section{RESULTS}

\subsection{Conversions}

One might expect that conversions of HOV lanes to HOT lanes would have a high B/C ratio. After all, the opportunity cost of the conversion is typically only a poorly performing $\mathrm{HOV}$ lane and the construction cost of the conversion is typically modest as well. However, the $\mathrm{B} / \mathrm{C}$ ratios of our three conversion cases range from 3.96 for Florida's I-95 express lanes to 0.23 for California's I-680 and -0.56 for Georgia's I- 85 project. As expected, the per lane-mile capital costs of the conversions were rather modest, ranging from $\$ 3.8$ million (Georgia I-85) and $\$ 5.2$ million (California I-680) to $\$ 9.6$ million (Florida I-95). But, with the exception of Florida, the time savings on both the general-purpose and the managed lanes were relatively trivial, typically less than a minute or two on a ten to fifteen-minute trip. In short, it appears that the circumstances that lead to a poorly performing HOV lane may also result in a poorly performing HOT lane.

\subsubsection{Florida's I-95 Express Lanes}

The extraordinary performance of Florida's 95 Express reflects reported average peak travel speeds ranging from 15 to $20 \mathrm{mph}$ the year before opening to 41 to $64 \mathrm{mph}$ the year after (FDOT 2011: 7). As shown in Table 3, this results in average savings 7.5 to 8.8 minutes on 
trips that formerly took 14 to 17 minutes. The Florida Department of Transportation (2014) estimated a B/C ratio of 6.97 for I-95 Express largely because they used a higher value of travel time saved and higher average vehicle occupancy than assumed in our estimates. The study also included safety and fuel savings benefits, although they were relatively small.

Table 3: Florida's I-95 Express Lanes Performance Summary

\begin{tabular}{|c|c|c|c|c|c|c|}
\hline \multirow[t]{2}{*}{ TRAFFIC IN PEAK } & \multicolumn{3}{|c|}{ General purpose lanes } & \multicolumn{3}{|c|}{ Managed lanes } \\
\hline & Before & After & Change & Before & After & Change \\
\hline Vehicles/day in peak & 67,417 & 71,316 & 3,899 & 19,741 & 25,926 & 6,997 \\
\hline Time, minutes/vehicle & 17.1 & 8.3 & $(8.8)$ & 14.5 & 7.0 & (7.5) \\
\hline BENEFITS & General & Managed & Total & & & \\
\hline Minutes saved/day & 576,544 & 257,461 & 834,005 & & & \\
\hline \multirow{2}{*}{ Time saved $\$ 000 / \mathrm{yr}$} & 40,838 & 18,237 & 59,075 & & & \\
\hline & \multicolumn{2}{|c|}{ Present value } & Typical year & & & \\
\hline Total benefits $\$ 000$ & 733,069 & & & & & \\
\hline \multicolumn{7}{|l|}{ COSTS $\$ 000$} \\
\hline \multicolumn{7}{|l|}{ COSTS \$000 } \\
\hline Operating & $(53,052)$ & \multicolumn{2}{|c|}{$\begin{array}{l}(10,637) \\
(4,275)\end{array}$} & & & \\
\hline Total & $(185,052)$ & \multicolumn{2}{|c|}{$(14,912)$} & & & \\
\hline NET BENEFIT & 548,017 & \multicolumn{2}{|c|}{44,163} & & & \\
\hline B/C RATIO & $7 \%$ (base & \multicolumn{2}{|c|}{$3 \%$} & & & \\
\hline$\$ 17 /$ hour (base case) & 3.96 & \multicolumn{2}{|c|}{5.37} & & & \\
\hline$\$ 34 /$ hour & 7.92 & \multicolumn{2}{|c|}{10.73} & & & \\
\hline$\$ 70 /$ hour & 16.31 & \multicolumn{2}{|c|}{22.09} & & & \\
\hline
\end{tabular}

\subsubsection{California's I-680 Southbound Express Lanes}

Our analysis of California's I-680 Southbound Express Lanes, summarized in Table 4, is based on comparing traffic volumes and speeds from 2008 with those in 2012, years when employment levels and gas prices in Alameda County were relatively similar. ${ }^{9}$ The I-680 experience is one of very small time savings leading to very modest changes in lane volumes. Motorists who continued to drive in the general-purpose lanes saved only 0.9 minutes (from 13.5 to 12.6 minutes) while those who stayed in the managed lanes saved only 0.3 minutes (from 11.5 to 11.2 minutes). The managed lanes were only 1.4 minutes faster than the generalpurpose lanes, too small a savings to encourage switching. The $\mathrm{B} / \mathrm{C}$ ratio for the base case is only 0.23 although it approaches or exceeds one if the value of travel time saved is $\$ 70$ per hour.

Table 4: California’s I-680 Southbound Express Lanes Performance Summary

\begin{tabular}{|c|c|c|c|c|c|c|}
\hline TRAFFIC IN PEAK & \multicolumn{3}{|c|}{ General purpose lanes } & \multicolumn{3}{|c|}{ Managed lanes } \\
\hline & Before & After & Change & Before & After & Change \\
\hline Vehicles/day in peak & 21,316 & 22,911 & 1,595 & 3,095 & 3192 & 98 \\
\hline Time, minutes/vehicle & 13.5 & 12.6 & $(0.9)$ & 11.5 & 11.2 & $(0.3)$ \\
\hline BENEFITS & General & Managed & Total & & & \\
\hline Minutes saved/day & 20,908 & 3,806 & 24,714 & & & \\
\hline \multirow[t]{2}{*}{ Time saved $\$ 000 / y r$} & 1,481 & 270 & 1,751 & & & \\
\hline & \multicolumn{2}{|c|}{ Present value } & al year & & & \\
\hline
\end{tabular}

\footnotetext{
${ }^{9}$ The southern section of the southbound lane is thought to have lost traffic in 2009-2010 to the improvement of a nearby intersection which, if true would cause the simple 2009-2012 comparison to overstate the benefits of the conversion to HOT (Alameda County Transportation Commission 2013: ES 9-12)
} 


\begin{tabular}{lll}
\cline { 2 - 3 } Total benefits \$000 & 21,723 & 1,751 \\
\hline COSTS \$000 & & \\
\hline Investment & $(36,634)$ & $(2,952)$ \\
Operating & $(55,841)$ & $(4,500)$ \\
Total & $(92,475)$ & $(7,452)$ \\
\hline NET BENEFIT & $(70,752)$ & $(5,702)$ \\
\hline B/C RATIO & $7 \%$ (base case) & $3 \%$ \\
\$17/hour (base case) & 0.23 & 0.27 \\
\$34/hour & 0.47 & 0.55 \\
\$70/hour & 0.97 & 1.13 \\
\hline
\end{tabular}

\subsubsection{Georgia's I-85 Express Lanes}

Georgia's I-85 Express Lanes are estimated to have a B/C ratio of negative 0.56, which means the users collectively lost rather than benefited and that their losses were 0.56 times the construction and operating costs of the lane conversion. Motorists traveling in the managed lanes in the peak period and peak direction saw their travel time decline by only 0.4 minutes (from 14.2 to 13.8 minutes) as toll paying SOVs replaced most of the HOV2s that had used the lanes previously. Meanwhile, motorists in the general-purpose lanes, whose vehicles outnumbered the vehicles in the managed lanes by almost ten to one, saw times increase by 1.3 minutes (from 16.1 to 17.4 minutes). The SOVs who switched to the managed lane saved 2.3 minutes (16.1 minus 13.8) but the HOV2s who they replaced lost 3.2 minutes (14.2 minus 17.4). Moreover, volumes decreased on both the managed and general-purpose lanes. The decrease in the general-purpose lanes is inconsistent with the reduction in travel times in those lanes; this suggests either measurement error or that some other factors were suppressing traffic besides the conversion, possibly the financial crisis, although it had been underway for two years before. USDOT $(2014 a, 61)$ specifically notes that "exogenous factors such as a more stable increase of gasoline prices in the post-deployment period and a slow but steady economic recovery potentially impacted the results" of this project. Additionally, "a vast majority of travelers that did not want to pay a toll did not adapt their travel behavior by shifting to 3person carpools or taking transit" (USDOT 2014a, 61). If, however, one simply blames all of the travel time losses in the general-purpose lanes to other factors, then the conversion has a $\mathrm{B} / \mathrm{C}$ ratio of 0.11 , much better but hardly encouraging. ${ }^{10}$

Table 5: Georgia's I-85 Express Lanes Performance Summary

\begin{tabular}{|c|c|c|c|c|c|c|}
\hline TRAFFIC IN PEAK & \multicolumn{3}{|c|}{ General purpose lanes } & \multicolumn{3}{|c|}{ Managed lanes } \\
\hline & Before & After & Change & Before & After & Change \\
\hline Vehicles/day in peak & 71,496 & 68,802 & $(2,694)$ & 9,429 & 8,608 & $(821)$ \\
\hline Time, minutes/vehicle & 16.1 & 17.4 & 1.3 & 14.2 & 13.8 & $(0.4)$ \\
\hline BENEFITS & General & Managed & Total & & & \\
\hline Minutes saved/day & $(95,029)$ & 15,866 & $(79,163)$ & & & \\
\hline \multirow[t]{2}{*}{ Time saved $\$ 000 / y r$} & $(6,731)$ & 1,124 & $(5,607)$ & & & \\
\hline & \multicolumn{2}{|c|}{ Present value } & Typical year & & & \\
\hline Total benefits $\$ 000$ & $(69,582)$ & \multicolumn{2}{|c|}{$(5,607)$} & & & \\
\hline \multicolumn{7}{|l|}{ COSTS \$000 } \\
\hline Investment & $(52,768)$ & \multicolumn{2}{|c|}{$(4,254)$} & & & \\
\hline Operating & $(71,839)$ & \multicolumn{2}{|c|}{$(5,789)$} & & & \\
\hline Total & $(124,625)$ & \multicolumn{2}{|c|}{$(10,043)$} & & & \\
\hline NET BENEFIT & $(194,207)$ & \multicolumn{2}{|c|}{$(15,650)$} & & & \\
\hline B/C RATIO & \multicolumn{2}{|c|}{$7 \%$ (base case) } & & & & \\
\hline
\end{tabular}

${ }^{10}$ This case may have also suffered from data quality issues (see, e.g. USDOT 2014a, 62). 


\subsection{MiXed PROJEcts}

\subsubsection{Washington's I-405 Express Lanes}

The evaluations of the Washington I-405 and Minnesota I-35W projects are complicated by the fact that they involve mixed approaches. The simpler of the two is Washington I-405 which is dominated by conversions but includes some new lanes as well. Our analysis, summarized in Table 6 , suggests a $\mathrm{B} / \mathrm{C}$ ratio of only 0.29 based on a comparison of performance just before the lanes opened in the fourth quarter of 2014 with performance a year later. The capital costs per lane mile were rather modest, but so were the changes in travel times and traffic volumes. Travel time improvements in both the managed and general-purpose lanes amounted to only 3.1 to 2.3 minutes respectively, on trips that took between 16 and 24 minutes. Motorists who switched from general-purpose lanes to managed lanes once tolling began saved 8.1 minutes (24.2-15.9). But this was a net gain of only 5.8 minutes (8.1-2.3), given that speeds were increasing in the general-purpose lanes anyway, and this savings was apparently not enough to induce many people to pay the toll.

Table 6: Washington's I-405 Express Lanes Performance Summary

\begin{tabular}{|c|c|c|c|c|c|c|}
\hline \multirow[t]{2}{*}{ TRAFFIC IN PEAK } & \multicolumn{3}{|c|}{ General purpose lanes } & \multicolumn{3}{|c|}{ Managed lanes } \\
\hline & Before & After & Change & Before & After & Change \\
\hline Vehicles/day in peak & 50,715 & 51,671 & 956 & 11,354 & 14,422 & 3,068 \\
\hline Time, minutes/vehicle & 24.2 & 21.9 & $(2.3)$ & 19.0 & 15.9 & $(3.1)$ \\
\hline BENEFITS & General & Managed & Total & & & \\
\hline Minutes saved/day & 109,060 & 106,303 & 215,363 & & & \\
\hline \multirow[t]{2}{*}{ Time saved $\$ 000 / y r$} & 7,725 & 7,530 & 15,255 & & & \\
\hline & \multicolumn{2}{|c|}{ Present value } & Typical year & & & \\
\hline Total benefits $\$ 000$ & 189,289 & \multicolumn{2}{|c|}{15,255} & & & \\
\hline \multicolumn{7}{|l|}{ COSTS $\$ 000$} \\
\hline Investment & $(155,500)$ & \multicolumn{2}{|c|}{$(12,531)$} & & & \\
\hline Operating & $(490,778)$ & \multicolumn{2}{|c|}{$(39,550)$} & & & \\
\hline Total & $(646,278)$ & \multicolumn{2}{|c|}{$(52,081)$} & & & \\
\hline NET BENEFIT & $(456,979)$ & \multicolumn{2}{|c|}{$(36,826)$} & & & \\
\hline B/C RATIO & $7 \%$ (base & \multicolumn{2}{|c|}{$3 \%$} & & & \\
\hline$\$ 17 /$ hour (base case) & 0.29 & \multicolumn{2}{|c|}{0.32} & & & \\
\hline$\$ 34 /$ hour & 0.59 & \multicolumn{2}{|c|}{0.64} & & & \\
\hline$\$ 70 /$ hour & 1.21 & \multicolumn{2}{|c|}{1.32} & & & \\
\hline
\end{tabular}

\subsubsection{Minnesota's I-35W Express Lanes}

As explained earlier, the I-35W project essentially consists of three projects in sequence on the southern approaches to downtown Minneapolis: the conversion of an existing HOV lane into a HOT lane, the rebuilding of an existing four-lane Crosstown Commons expressway with an added HOT Lane, and, finally, the creation of a new HOT Lane on the shoulders of the existing city center expressway. Time savings are considerable despite large increases in traffic volumes, particularly on Crosstown Commons section. During the morning inbound peak, motorists who stay in the general-purpose lanes or who switch from the general-purpose to the managed lanes save roughly 5 minutes, slightly more than half on the southernmost HOT lanes and a half on the Crosstown Commons while time is lost on the PDSL. Motorists traveling 
during the evening outbound peak save slightly less than 4 minutes, again a half on the Crosstown Commons and a half on the southernmost HOT lanes. These figures are similar to those reported elsewhere (FHWA 2015, 13)

Overall, the project has a respectable $\mathrm{B} / \mathrm{C}$ ratio of 1.32 . It is difficult to separate the contributions of the different segments, especially since the several HOT lanes are in sequence so that if one were missing the traffic would presumably backup in the system. Nevertheless, if one ignores the potential to form bottlenecks and simply allocates the capital costs and the travel time savings to the different segments, then it appears as if both the converted lanes to the south and the new lanes in Crosstown Commons are contributing roughly equally to the system performance. If the Crosstown Commons is considered separately, for example, the $\mathrm{B} / \mathrm{C}$ ratio is 1.56 , virtually the same as for the system as a whole.

Table 7: Minnesota's I-35W Express Lanes Performance Summary

\begin{tabular}{|c|c|c|c|c|c|c|}
\hline \multirow[t]{2}{*}{ TRAFFIC IN PEAK } & \multicolumn{3}{|c|}{ General purpose lanes } & \multicolumn{3}{|c|}{ Managed lanes } \\
\hline & Before & After & Change & Before & After & Change \\
\hline Vehicles/day in peak & 33,197 & 42,051 & 8,854 & - & 4,656 & - \\
\hline Time, minutes/vehicle & 18.6 & 14.9 & (3.8) & - & 13.7 & - \\
\hline BENEFITS & General & Managed & Total & & & \\
\hline Minutes saved/day & 158,729 & 10,874 & 169,602 & & & \\
\hline \multirow{2}{*}{ Time saved $\$ 000 / \mathrm{yr}$} & 11,243 & 770 & 12,013 & & & \\
\hline & \multicolumn{2}{|c|}{ Present value } & Typical year & & & \\
\hline Total benefits $\$ 000$ & 149,076 & & & & & \\
\hline \multicolumn{7}{|l|}{$\begin{array}{l}\text { Total benefits } \$ 000 \\
\text { COSTS } \$ 000\end{array}$} \\
\hline \multicolumn{7}{|l|}{ Investment } \\
\hline Operating & $(10,381)$ & \multicolumn{2}{|c|}{ (837) } & & & \\
\hline Total & $(106,997)$ & \multicolumn{2}{|c|}{$(8,623)$} & & & \\
\hline NET BENEFIT & 42,078 & \multicolumn{2}{|c|}{3,391} & & & \\
\hline B/C RATIO & \multicolumn{2}{|c|}{$7 \%$ (base case) } & $3 \%$ & & & \\
\hline$\$ 17 /$ hour (base case) & 1.32 & \multicolumn{2}{|c|}{2.08} & & & \\
\hline$\$ 34 /$ hour & 2.79 & \multirow{2}{*}{\multicolumn{2}{|c|}{$\begin{array}{l}4.17 \\
850\end{array}$}} & & & \\
\hline \$70/hour & 5.74 & & & & & \\
\hline
\end{tabular}

\subsubsection{North Tarrant and LBJ Express Lanes}

The North Tarrant Expressway and LBJ Expressway projects are very similar in that they both are 13.3 miles long, cost in excess of $\$ 2$ billion and involve a mix, depending on the segment, of the construction of 2 to 3 new managed lanes, the rebuilding of 3 to 4 general purpose lanes and the construction of 2 frontage lanes in each direction. The North Tarrant was fully operational in October 2014 and the LBJ in September 2015. 2010 is used as the before year and 2016 as the after year because of extensive construction disruption in the years before opening. As noted earlier, the base case assumes that the general-purpose lanes would have had to be rebuilt anyway and thus assigns only 40 percent of construction and operating costs to the managed lanes.

One potentially important difference between the North Tarrant and LBJ managed lanes and the other five cases, however, is that the former connect two metropolitan centers-Dallas and Fort Worth - rather than one and thus are heavily used during the midday as well as during peak commuting directions and hours. To see how this might affect the results, we estimated $\mathrm{B} / \mathrm{C}$ ratios for a 12-hour day $(6 \mathrm{am}-6 \mathrm{pm})$ as well as for the six peak hours (6-9 am and 4-7 $\mathrm{pm})$. On the North Tarrant Expressway, the six-hour B/C ratio is 0.24 or roughly three-fifths 
of the 12-hour B/C ratio of $0.41 .{ }^{11}$ Lacking twelve-hour volumes and speeds from most of our sample, we can't rule out the possibility that our assumption of six peak hours significantly affects the $\mathrm{B} / \mathrm{C}$ ratios on some types of HOT lanes.

The North Tarrant Expressway consists of two connecting East-West segments and their combined daily traffic during the six peak hours increased by slightly more than half from 97,255 to 149,228 vehicles with two-thirds of the increase on the managed lanes $(33,390$ vehicles) and one-third on the general-purpose lanes (18,633 vehicles). These shifts in traffic were stimulated by savings of 4 to 6 minutes on trips across the two segments that previously required 14 to 18 minutes (see Table 8). Eastbound in the afternoon peak, for example, travel times dropped from 16.7 to 12.7 minutes on the general-purpose lanes and to only 10.7 minutes on the managed lanes for a savings of 4 minutes for motorists who stayed in the general lanes and 6 minutes for those who switched to the managed lanes. The resulting benefits were enough to offset roughly half of the operating expenses and make a small contribution to the considerable capital expenses.

The LBJ has performed much more poorly with six-hour and twelve-hour B/C ratios of 0.03 and 0.04 respectively (see Table 9). ${ }^{12}$ The LBJ has four general purpose lanes instead of three and is divided in three segments: a North-South segment connecting with two East-West segments. During the six peak hours, travel on all three segments increased by only one eighth (from 256,050 to 288,676 vehicles) with the managed lanes attracting roughly a fifth of the users $(56,335$ vehicles) while the general-purpose lanes actually lost users, falling to a fourfifths share (232,341 vehicles).

Table 8: North Tarrant Expressway Performance Summary

\begin{tabular}{|c|c|c|c|c|c|c|}
\hline TRAFFIC IN PEAK & \multicolumn{3}{|c|}{ General purpose lanes } & \multicolumn{3}{|c|}{ Managed lanes } \\
\hline & Before & After & Change & Before & After & Change \\
\hline Vehicles/day in peak & 48,305 & 57,807 & 9,502 & - & 16,762 & - \\
\hline Time, minutes/vehicle & 8.2 & 6.8 & (1.4) & - & 5.4 & - \\
\hline BENEFITS & General & Managed & Total & & & \\
\hline Minutes saved/day & 156,701 & 99,744 & 256,446 & & & \\
\hline \multirow{2}{*}{ Time saved $\$ 000 / \mathrm{yr}$} & 11,100 & 7,065 & 18,165 & & & \\
\hline & \multicolumn{2}{|c|}{ Present value } & Typical year & & & \\
\hline Total benefits $\$ 000$ & 225,409 & & & & & \\
\hline \multicolumn{7}{|l|}{ COSTS $\$ 000$} \\
\hline Investment & \multirow{2}{*}{\multicolumn{2}{|c|}{$(840,000)$}} & $(67,693)$ & & & \\
\hline Operating & & & & & & \\
\hline Total & \multicolumn{2}{|l|}{$(939,272)$} & $(75,693)$ & & & \\
\hline NET BENEFIT & \multicolumn{2}{|l|}{$(713,863)$} & $(57,528)$ & & & \\
\hline B/C RATIO & \multicolumn{2}{|c|}{$7 \%$ (base case) } & $3 \%$ & & & \\
\hline$\$ 17 /$ hour (base case) & 0.24 & \multicolumn{2}{|c|}{0.36} & & & \\
\hline$\$ 34 /$ hour & 0.48 & \multicolumn{2}{|c|}{0.71} & & & \\
\hline$\$ 70 /$ hour & 0.99 & & $\begin{array}{l}0.71 \\
1.47\end{array}$ & & & \\
\hline
\end{tabular}

Table 9: LBJ Expressway Performance Summary

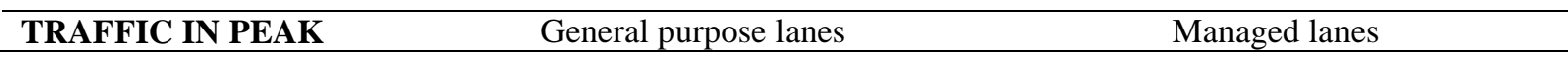

\footnotetext{
${ }^{11}$ On the North Tarrant, the annual time savings increase from $\$ 18,165$ thousand for the six peak hours to $\$ 30,878$ thousand for the 12 hour day. Given costs of $\$ 75,693$ thousand the $\mathrm{B} / \mathrm{C}$ ratios are 0.24 and 0.41 .

${ }^{12}$ On the LBJ, the annual time savings fall from $\$ 2,814$ thousand for the six peak hours to $\$ 406$ thousand for the 12 hour day. The savings fall because travel times increase rather than fall in many segments during the midday. Given costs of $\$ 91,810$ thousand, the $\mathrm{B} / \mathrm{C}$ ratios are 0.03 and 0.004 .
} 


\begin{tabular}{|c|c|c|c|c|c|c|}
\hline & Before & After & Change & Before & After & Change \\
\hline Vehicles/day in peak & 85,489 & 78,450 & $(7,039)$ & - & 20.107 & - \\
\hline Time, minutes/vehicle & 5.3 & 5.7 & 0.3 & - & 3.9 & - \\
\hline BENEFITS & General & Managed & Total & & & \\
\hline Minutes saved/day & $(69,577)$ & 109,302 & 39,725 & & & \\
\hline \multirow[t]{2}{*}{ Time saved $\$ 000 / \mathrm{yr}$} & $(4,928)$ & 7,742 & 2,814 & & & \\
\hline & \multicolumn{2}{|c|}{ Present value } & Typical year & & & \\
\hline Total benefits $\$ 000$ & 34,917 & \multicolumn{2}{|c|}{2,814} & & & \\
\hline \multicolumn{7}{|l|}{ COSTS $\$ 000$} \\
\hline Investment & \multirow{2}{*}{\multicolumn{2}{|c|}{$\begin{array}{l}(1,040,000) \\
(99,272)\end{array}$}} & $(83,810)$ & & & \\
\hline Operating & & \multicolumn{2}{|c|}{$(8,000)$} & & & \\
\hline Total & \multicolumn{2}{|l|}{$(1,139,272)$} & $(91,810)$ & & & \\
\hline NET BENEFIT & \multicolumn{2}{|l|}{$(1,104,335)$} & $(88,996)$ & & & \\
\hline B/C RATIO & \multicolumn{2}{|l|}{$7 \%$ (base case) } & $3 \%$ & & & \\
\hline$\$ 17 /$ hour (base case) & \multicolumn{2}{|l|}{0.03} & 0.05 & & & \\
\hline$\$ 34 /$ hour & \multicolumn{2}{|l|}{0.06} & 0.09 & & & \\
\hline$\$ 70 /$ hour & \multicolumn{3}{|l|}{0.13} & & & \\
\hline
\end{tabular}

These disappointing results stem from the fact that the weighted average time savings per segment on the LBJ are lower than those of the North Tarrant expressway (compare Tables 8 and 9). The LBJ's third segment performs particularly poorly with travel times in the generalpurpose lanes during the PM peak actually increasing by 2.7 minutes westbound and 1.6 minutes eastbound.

The operators of the LBJ blame construction by the Texas Department of Transportation on another expressway that connects with the third segment for creating backups on the LBJ. If so, the performance should improve when the other expressway is finished. Sensitivity analyses which excluded the segments experiencing time losses suggest that the LBJ may not perform as well as the North Tarrant once the backups are eliminated, however. ${ }^{13}$

\section{SENSITIVITY ANALYSES}

Sensitivity analyses, summarized in Table 10, show that the B/C ratios are far more sensitive to the VOT saved and the proportion of costs that are assigned to managed lanes than to the discount rate. Assuming \$17 per vehicle hour and a 7\% discount rate, only two of the seven projects have a benefit cost-ratio above 1.0 (Florida I-95 and Minnesota I-35W). When the VOT is increased to $\$ 70 /$ vehicle hour, three more cases have benefit cost-ratios of 1.0 or very close to 1.0. However, when the VOT is kept at $\$ 70 /$ hour but the discount rate is dropped to $3 \%$, there is little to no effect on the number of cases that have a $\mathrm{B} / \mathrm{C}$ ratio of one or more.

Table 10: Summary of Estimates of B/C Ratios

\begin{tabular}{|l|c|c|cccccc|}
\cline { 3 - 8 } \multicolumn{2}{c|}{} & \multicolumn{5}{c|}{ Scenarios (VOT, Discount Rate) } \\
\hline Project & $\begin{array}{c}\text { Benefit } \\
\text { Scenario }\end{array}$ & $\begin{array}{c}\text { Cost } \\
\text { Scenario }\end{array}$ & $\$ 17,7 \%$ & $\$ 17,3 \%$ & $\$ 34,7 \%$ & $\$ 34,3 \%$ & $\$ 70,7 \%$ & $\$ 70,3 \%$ \\
\hline $\begin{array}{l}\text { Florida's I-95 } \\
\text { Express Lanes }\end{array}$ & Base & $100 \%$ & 3.96 & 5.34 & 7.92 & 10.73 & 16.31 & 22.09 \\
\hline $\begin{array}{l}\text { California's I-680 } \\
\text { SB Express Lanes }\end{array}$ & Base & $100 \%$ & 0.23 & 0.27 & 0.47 & 0.55 & 0.97 & 1.13 \\
\hline
\end{tabular}

\footnotetext{
${ }^{13}$ Ignoring the segments and hours when travel times increase, user time savings rise for a six-hour day from $\$ 2,814$ thousand to $\$ 7,742$ thousand. With costs of $\$ 91,810$ thousand, the $\mathrm{B} / \mathrm{C}$ ratio increases from 0.03 to 0.08 . (In Table 10, compare the optimistic and base cases if only $40 \%$ of costs are assigned to managed lanes.)
} 


\begin{tabular}{|c|c|c|c|c|c|c|c|c|}
\hline \multirow{2}{*}{$\begin{array}{l}\text { Georgia's I-85 } \\
\text { Express Lanes }\end{array}$} & Optimistic & $100 \%$ & 0.11 & 0.13 & 0.22 & 0.26 & 0.46 & 0.55 \\
\hline & Base & $100 \%$ & -0.56 & -0.66 & -1.12 & -1.32 & -2.30 & -2.72 \\
\hline $\begin{array}{l}\text { Washington's I- } \\
405 \text { Express } \\
\text { Lanes }\end{array}$ & Base & $100 \%$ & 0.29 & 0.32 & 0.59 & 0.64 & 1.21 & 1.32 \\
\hline \multirow{2}{*}{$\begin{array}{l}\text { Minnesota's I- } \\
35 \text { W Express } \\
\text { Lanes }\end{array}$} & Base & $\begin{array}{c}25 \% \text { of } \\
\text { Crosstown }\end{array}$ & 1.32 & 2.08 & 2.79 & 4.17 & 5.74 & 8.58 \\
\hline & Base & $100 \%$ & 0.54 & 0.83 & 1.07 & 1.66 & 2.21 & 3.41 \\
\hline \multirow{2}{*}{$\begin{array}{l}\text { Texas' North } \\
\text { Tarrant Express } \\
\text { Lanes }\end{array}$} & Base & $40 \%$ & 0.24 & 0.36 & 0.48 & 0.71 & 0.99 & 1.47 \\
\hline & Base & $100 \%$ & 0.10 & 0.14 & 0.19 & 0.29 & 0.40 & 0.59 \\
\hline \multirow{4}{*}{$\begin{array}{l}\text { Texas'LBJ } \\
\text { Express Lanes }\end{array}$} & Base & $40 \%$ & 0.03 & 0.05 & 0.06 & 0.09 & 0.13 & 0.19 \\
\hline & Optimistic & $40 \%$ & 0.08 & 0.13 & 0.17 & 0.25 & 0.35 & 0.52 \\
\hline & Base Case & $100 \%$ & 0.01 & 0.02 & 0.02 & 0.04 & 0.05 & 0.08 \\
\hline & Optimistic & $100 \%$ & 0.03 & 0.05 & 0.07 & 0.10 & 0.14 & 0.21 \\
\hline
\end{tabular}

\section{DISCUSSION}

One of the most prominent takeaways from our BCA is that VOT assumptions have a large influence on project $\mathrm{B} / \mathrm{C}$ ratios. These results seem to indicate that the "value of an uncongested travel alternative (such as MLs) is ... greatly undervalued if using typical [value of travel time savings] VTTS estimates" (Patil, Burris, Shaw, and Concas 2011, 547). Our base VOT assumption of $\$ 17$ per hour likely excludes any benefit for reliability and does not recognize any variation in value or any sorting by value between managed and general-purpose lanes users. Devarasetty, Burris, and Shaw's (2012) survey of 3,325 travelers who use Houston's Katy Freeway managed lanes appears to confirm our concern. Their study shows that the combined value of time and value of reliability for Katy Freeway managed lane travelers is $\$ 61 /$ hour, with travel time savings and travel time reliability making up $48 \%$ and $56 \%$ of the sample mean hourly wage rate respectively. ${ }^{14}$ As we suspected, "it appears that travelers are factoring in (consciously or subconsciously) some additional value for the reliability of [managed lanes] when they choose to use these lanes (Devarasetty, Burris, and Shaw 2012, 56). According to Burris and Patil $(2009,7)^{15}$ :

[t]his [underestimation of ML VTTS] has significant policy implications since the benefits of MLs (and of most transportation investments) are primarily derived from travel time savings. Underestimating the value of ML travel time savings underestimates the benefits of MLs, reducing the likelihood of funding such facilities.

In light of these considerations, our final VOT assumption of $\$ 70 /$ hour in the BCA appears to be a far more realistic estimate of VOT for managed lane travelers. This assumption also offers more promising results for the seven managed lane projects we analyzed-i.e. five out of seven projects achieve $\mathrm{B} / \mathrm{C}$ ratios of better than, or very close to, one. Likewise, those projects which still fail the BCA test may also be affected by inefficient toll-setting, additional development

\footnotetext{
${ }^{14}$ Value is close to the value travelers place on their travel time for actual trips on the Kay Freeway (i.e. average of $\sim \$ 51 / \mathrm{hr}$.).

15 Burris and Patil (2009) use survey data collected from Katy Freeway travelers in Houston, Texas, to estimate the difference in the value of travel time savings (VTTS) between ordinary and urgent travel situations for the managed lane (ML) travelers.
} 
costs, poor managed-lane design, congestion on connecting highways, and/or other, unobserved exogenous factors.

Overall, the results from our BCA and sensitively analysis offer a complicated picture of toll-managed lane efficacy and should be interpreted with caution. This is because "toll road traffic forecasts are characterised by large errors and considerable optimism bias" (Bain 2009, 469; see also JP Morgan 1997). Flyvbjerg, Holm, and Buhl $(2006,1)$ note that, "[f]or 50\% of road projects, the difference between actual and forecasted traffic is more than $\pm 20 \%$; for $25 \%$ of road projects, the difference is larger than $\pm 40 \%$." Our BCA study took an overly conservative approach to traffic forecasting to address this issue, one which surely understates traffic attributable to these projects. Moreover, our low B/C ratios based on year 1 volumes are not terribly surprising, especially for MLs built by private firms. Because many of these companies are searching for "diamonds in the rough," they tend to pursue ML opportunities that DOTs are not looking and/or able to build now and expect their gambles to payoff longterm. Although these effects may not be completely captured in our analysis, our estimated $\mathrm{B} / \mathrm{C}$ ratios still appear to be within the same order of magnitude as previous BCA studies (see, e.g. FHWA 2015), a result which supports our methodology and underlying assumptions.

\section{CONCLUSIONS}

Since the opening of SR-91, toll-managed lanes have spread relatively rapidly into at least a half-dozen states throughout the United States. In many cases, public officials have embraced toll-managed lanes as a way of squeezing out more capacity from existing expressway lanes and/or financing the construction of new expressway lanes in congested urban areas. Although these projects have risen in popularity in recent years, the benefits and costs associated with toll-managed lanes are not well documented. Our paper attempts to fill this gap by examining whether toll-managed lanes are as beneficial as they are popular. While it is hazardous to generalize about the characteristics of managed lane facilities from a sample of only seven projects, three main conclusions emerge from our simplified BCA.

First, our results paint a complicated picture of toll-managed lane efficacy. Our base case scenarios are rather discouraging in that five of the seven projects studied have $\mathrm{B} / \mathrm{C}$ ratios well below one. Moreover, success does not appear to depend on the scale of the project or the investment required-some costly projects are beneficial, and some inexpensive projects are not. However, our base case analyses likely underestimate the benefits of toll managed lanes in several ways. For example, by assuming that the full effect of a managed lane materializes in the first year, we surely understate traffic attributable in greenfield environments, although not necessarily the hours saved.

Second, a necessary key to success is a significant time savings for users of the managed lanes over users of the general-purpose lanes. Our more successful projects typically offer users who shift to the managed lanes time savings of around 4 to 5 minutes on road segments that previously required around 15 minutes to traverse, or enough to make the gain noticeable. The best projects also offer savings of 1 to 2 minutes per trip for motorists who continue to use the general-purpose lanes. Even small, time gains and losses in the general-purpose lanes can have an important effect on the net benefits because the general-purpose lanes typically carry several times the traffic as the tolled lanes. Many other researchers have reached similar conclusions, noting that the time savings depends upon the existence of chronic congestion in the general purpose lanes, excess capacity in the HOT lane, and a long enough lane to make the speed difference result in a noticeable time savings (see e.g. Ungemah and Swisher 2006; Fitch 2017). It is therefore not surprising that one of the most important and obvious criteria for success is a noticeably large time savings for the users of the toll-managed lane.

Finally, a better understanding of the value motorists place on reducing travel time and improving reliability is important in evaluating managed lanes. Many transportation planners 
believe that motorists care about the reliability of travel time as much as they care about average travel time. Additionally, evidence suggests motorists vary in the value they place on time and reliability, and those who value time and reliability the most use managed lanes. However, there remains little consensus on how the value of reliability should be measured.

In our seven cases, simple calculations of the implicit value that managed lane users place on time and reliability suggest that we have been underestimating the value of reliability for managed lanes. In our base case, a \$17 per hour assumption for the value of time of motorists likely excludes any benefit for reliability and does not recognize any variation in value or any sorting by value between managed and general-purpose lanes. As a result, this estimate probably also underestimates the benefits of the toll-managed lanes by understating the value of an hour of travel time saved. If we double this value to $\$ 34$ per hour to recognize reliability, it is still not enough to significantly affect the number of cases with $\mathrm{B} / \mathrm{C}$ ratios above one. However, if when we assume an implicitly revealed value closer to $\$ 70$ per hour on the basis of heterogeneity and sorting, then five out of seven projects have $\mathrm{B} / \mathrm{C}$ ratios of better than, or very close to, one. The projects which still suffer from $\mathrm{B} / \mathrm{C}$ ratios less than one may also be affected by inefficient toll-setting, additional development costs, poor managed-lane design (e.g. Georgia I-85), congestion on connecting highways (e.g. LBJ Expressway), and/or other, unobserved exogenous factors. Future research should explore these issues and their ultimate impact on toll-managed lane efficacy.

\section{ACKNOWLEDGMENTS}

Special thanks to Mark Fagan and John Foote for their valuable guidance and feedback.

\section{FUNDING}

This study was funded in part by the United States Department of Transportation (USDOT) through the New England Region University Transportation Center at the Massachusetts Institute of Technology (MIT).

\section{REFERENCES}

Alameda County Transportation Commission. 2013. "The Southbound Interstate 680 (I-680) Express Lane Performance Evaluation: An After Study." Report to the Commission by Kittelson and Associates, Inc.

Bain, Robert. 2009. "Error and optimism bias in toll road traffic forecasts."

Transportation 36, no. 5: 469-482.

Beckmann, Martin J. 1967. "On optimal tolls for highways, tunnels, and bridges. in vehicular traffic science." In Proceedings of the Third International Symposium on the Theory of Traffic FlowOperations Research Society of America.

Buckeye, Kenneth. 2012. "Performance Evaluation of I-394 MnPASS Express Lanes in

Minnesota." Transportation Research Record: Journal of the Transportation Research

Board 2278, no. 1: 153-162.

Buckeye, Kenneth. 2014. "Express Lane Performance Evaluation: I-35W in Minnesota."

Transportation Research Record: Journal of the Transportation Research Board 2450

(Revenue, Finance, Pricing and Economics): 36-43.

Burris, Mark W., and John F. Brady. 2018. "Unrevealed Preferences: Unexpected Traveler

Response to Pricing on Managed Lanes." Transportation Research Record 2672, no. 5: 23-32.

Burris, Mark, and Edward Sullivan. 2006. "Benefit-cost analysis of variable pricing projects: QuickRide HOT lanes." Journal of Transportation Engineering 132, no. 3: 183-190. 
Burris, Mark, and Sunil Patil. 2009. "Estimating the Benefits of Managed Lanes: Final Report." College Station, TX: University Transportation Center for Mobility (UTCM), Texas Transportation Institute.

Collier, Tina, and Ginger Goodin. 2004. "Managed lanes: A cross-cutting study." College Station, TX: Texas Transportation Institute.

Devarasetty, Prem Chand, Mark Burris, and W. Douglass Shaw. 2012. "Do travelers pay for managed-lane travel as they claimed they would? Before-and-after study of travelers on Katy Freeway, Houston, Texas." Transportation Research Record 2297, no. 1: 56-65.

d'Ouville, Edmond L., and John F. McDonald. 1990. "Optimal road capacity with a suboptimal congestion toll." Journal of Urban Economics 28, no. 1: 34-49.

FDOT. 2010b. "2010 I-95 High Occupancy Vehicle Lane Monitoring Report.” Prepared by Cambridge Systematics, Inc. with Kimley-Horn and Associates, Inc.

FDOT. 2011. "95 Express Annual Report: Covering July 1, 2010 through June 30, 2011." District Six, Florida Department of Transportation.

FDOT. 2013. "95 Express Annual Report: Covering July 12011 through June 30, 2012.” District Six, Florida Department of Transportation.

FDOT. 2014. "Tool for Operations Benefit/Cost (TOPS-BC) for Florida DOT Applications." Prepared by Cambridge Systematics. Task Work Order 20, Sub Task 4.

Federal Highway Administration (FHWA). 2012. "Price Managed Land Guide." Washington, DC: US Department of Transportation.

Ferrari, Paolo. 2002. "Road network toll pricing and social welfare." Transportation Research Part B: Methodological 36, no. 5: 471-483.

FHWA. 2015. "Contemporary Approaches in Congestion Pricing: Lessons Learned from the National Evaluation of Congestion Pricing Strategies at Six Sites." Report FHWA-JPO2015-217. Washington, DC: US Department of Transportation.

FHWA 2016. "Report on Highway Public-Private Partnership Concessions in the United States." BATIC Center and Office of Innovative Program Delivery, US Department of Transportation.

Fitch Ratings. 2013. "U.S. Managed Lanes: Empirical Data Steers Credit Analysis.” Special Report, Global Infrastructure and Project Finance.

Fitch Ratings. 2017. "Peer Review of U.S. Managed Lanes: Attribute Assessments and Ratings." Global Infrastructure and Project Finance.

Florida Department of Transportation (FDOT). 2010a. "District Six-95 Express Monthly Operations Report - July."

Flyvbjerg, Bent, Mette K. Skamris Holm, and Søren L. Buhl. 2006. "Inaccuracy in traffic forecasts." Transport Reviews 26, no. 1: 1-24.

Moody’s Investor Service. May 2013. "Managed Lanes are HOT! Unique Risks and Benefits versus Conventional Tolling."

Morgan, JP. 1997. "Examining toll road feasibility studies." Municipal Finance Journal 18. No. 1: 1-12.

Obenberger, Jon. 2004. "Managed lanes." Public Roads 68, no. 3: 48-55.

Patil, Sunil, Mark Burris, W. Douglass Shaw, and Sisinnio Concas. 2011. "Variation in the value of travel time savings and its impact on the benefits of managed lanes." Transportation Planning and Technology 34, no. 6: 547-567.

Poole, Robert, and C. Kenneth Orski. 2000. "HOT lanes: A better way to attack urban highway congestion." Regulation 23: 15.

Poole, Robert. 2014. "Keys to Financing Managed Lane Networks." Reason Foundation.

Poole, Robert. April 2017. "Express Toll Lanes Progress and Setbacks" Reason Foundation, Surface Transportation Innovations Issue 162. 
Regan, Ed. 2009. "Bottom Line: HOT Lanes Are Not All They Are Cooked Up To Be." Public Works Financing Newsletter. Vol. 237, April.

Regard, Ed. 2017. "Keeping the Promise: Saving Managed Lanes for their Own Success." Public Works Financing Newsletter. Vol. 324, March.

Sanchez, Ricardo. July 2016. "NTE/LBJ Managed Lanes Facts and Benefits.” Slide presentation.

Small, Kenneth A. and Jia Yan. 2001. "The Value of "Value Pricing of Roads: Second-best Pricing and Product Differentiation." Journal of Urban Economics 49: 310-336.

Small, Kenneth A., Clifford Winston and Jia Yan. 2005. "Uncovering the Distribution of Motorists' Preferences for Travel Time and Reliability." Econometrica 73, no. 4: 13671382.

Starkie, David. 1986. "Efficient and politic congestion tolls." Transportation Research Part A: General 20, no. 2: 169-173.

Sullivan, Edward, and Mark Burris. 2006. "Benefit-cost analysis of variable pricing projects: SR-91 express lanes." Journal of Transportation Engineering 132, no. 3: 191-198.

Schwimmer, Emily, José A. Gómez-Ibáñez, and Carter B. Casady. 2019. "Toll-Managed Lane Pioneers: Lessons from Five US States." Case Studies on Transport Policy 7, no. 3: 655-666.

Ungemah, David and Myron Swisher. 2006. "So you Want to Make a High-Occupancy Toll Lane?" Transportation Research Record: Journal of the Transportation Research Board no. 1960: 94-98.

US Department of Transportation (USDOT). 2013. "Urban Partnership Agreement: Minnesota Evaluation Report." Research and Innovative Technology Administration, Federal Highway Administration. FHWA-JPO-13-048.

USDOT. 2014a. "Atlanta Congestion Reduction Demonstration National Evaluation Report." Research and Innovative Technology Administration, Federal Highway Administration. FHWA-JPO-14-152

USDOT. 2014b. " The Value of Travel Time Savings: Departmental Guidance for Conducting Economic Evaluations (revision 2)." Office of Secretary of Transportation, USDOT.

Washington State Department of Transportation (WSDOT). 2010. "East Side Corridor Tolling Study." Prepared for Washington State Legislature.

Wilson, John D. 1983. "Optimal road capacity in the presence of unpriced congestion." Journal of Urban Economics 13, no. 3: 337-357.

WSDOT. 2013. "I-405-NE 6th to I-5 Widening and Express Toll Lanes." Washington State Department of Transportation.

WSDOT. 2016a. "I-405/SR 167 Corridor: Executive Advisor Group." Washington State Department of Transportation.

WSDOT. 2016b. "I-405 Express Toll Lanes Six Month Update.” Washington State

Department of Transportation.

\section{APPENDIX A: BENEFIT-COSTS DETAILED RESULTS FOR SEVEN CASES}

Table A-1: MN I-35W (Full Cost of Crosstown Reconstruction)

\begin{tabular}{|c|c|c|c|c|c|c|}
\hline TRAFFIC IN PEAK & \multicolumn{3}{|c|}{ General purpose lanes } & \multicolumn{3}{|c|}{ Managed lanes } \\
\hline & Before & After & Change & Before & After & Change \\
\hline Vehicles/day in peak & 33,197 & 42,051 & 8,854 & - & 4,656 & - \\
\hline Time, minutes/vehicle & 18.6 & 14.9 & $(3.8)$ & - & 13.7 & - \\
\hline BENEFITS & General & Managed & Total & & & \\
\hline Minutes saved/day & 158,729 & 10,874 & 169,602 & & & \\
\hline
\end{tabular}




\begin{tabular}{lll} 
Time saved \$000/yr & \multicolumn{1}{c}{11,243} & \multicolumn{1}{c}{12,013} \\
\cline { 2 - 3 } Total benefits $\$ 000$ & Present value & \multicolumn{1}{c}{ Typical year } \\
\cline { 2 - 3 } COSTS \$000 & 149,076 & 12,013 \\
\hline Investment & $(267,616)$ & $(21,566)$ \\
Operating & $(10,381)$ & $(837)$ \\
Total & $(277,997)$ & $(22,403)$ \\
\hline NET BENEFIT & $(128,922)$ & $(10,389)$ \\
\hline B/C RATIO & $7 \%$ (base case) & $3 \%$ \\
\$17/hour (base case) & 0.54 & 0.83 \\
\$34/hour & 1.07 & 1.66 \\
\$70/hour & 2.21 & 3.41 \\
\hline
\end{tabular}

Table A-2: MN I-35W (Base: Adjusted Cost 25\% of Crosstown Reconstruction)

\begin{tabular}{|c|c|c|c|c|c|c|}
\hline \multirow[t]{2}{*}{ TRAFFIC IN PEAK } & \multicolumn{3}{|c|}{ General purpose lanes } & \multicolumn{3}{|c|}{ Managed lanes } \\
\hline & Before & After & Change & Before & After & Change \\
\hline Vehicles/day in peak & 33,197 & 42,051 & 8,854 & - & 4,656 & - \\
\hline Time, minutes/vehicle & 18.6 & 14.9 & $(3.8)$ & - & 13.7 & - \\
\hline BENEFITS & General & Managed & Total & & & \\
\hline Minutes saved/day & 158,729 & 10,874 & 169,602 & & & \\
\hline \multirow[t]{2}{*}{ Time saved $\$ 000 / \mathrm{yr}$} & 11,243 & 770 & 12,013 & & & \\
\hline & \multicolumn{2}{|c|}{ Present value } & Typical year & & & \\
\hline \multirow{2}{*}{\multicolumn{7}{|c|}{$\begin{array}{l}\text { Total benefits } \$ 000 \\
\text { COSTS } \$ 000\end{array}$}} \\
\hline & & & & & & \\
\hline Investment & \multicolumn{2}{|l|}{$(96,616)$} & $(7,786)$ & & & \\
\hline Operating & \multicolumn{2}{|l|}{$(10,381)$} & $(837)$ & & & \\
\hline Total & \multicolumn{2}{|l|}{$(106,997)$} & $(8,623)$ & & & \\
\hline NET BENEFIT & \multicolumn{2}{|l|}{42,078} & 3,391 & & & \\
\hline B/C RATIO & \multicolumn{2}{|c|}{$7 \%$ (base case) } & $3 \%$ & & & \\
\hline$\$ 17 /$ hour (base case) & \multicolumn{2}{|l|}{1.32} & 2.08 & & & \\
\hline$\$ 34 /$ hour & \multicolumn{2}{|l|}{2.79} & 4.17 & & & \\
\hline$\$ 70 /$ hour & \multicolumn{3}{|l|}{5.74} & & & \\
\hline
\end{tabular}

Table A-3: GA I-85 (Optimistic)

\begin{tabular}{|c|c|c|c|c|c|c|}
\hline \multirow[t]{2}{*}{ TRAFFIC IN PEAK } & \multicolumn{3}{|c|}{ General purpose lanes } & \multicolumn{3}{|c|}{ Managed lanes } \\
\hline & Before & After & Change & Before & After & Change \\
\hline Vehicles/day in peak & 71,496 & 68,802 & $(2,694)$ & 9,429 & 8,608 & $(821)$ \\
\hline Time, minutes/vehicle & 16.1 & 17.4 & 1.3 & 14.2 & 13.8 & $(0.4)$ \\
\hline BENEFITS & General & Managed & Total & & & \\
\hline Minutes saved/day & - & 15,866 & 15,866 & & & \\
\hline \multirow[t]{2}{*}{ Time saved $\$ 000 / \mathrm{yr}$} & - & 1,124 & 1,124 & & & \\
\hline & \multicolumn{2}{|c|}{ Present value } & Typical year & & & \\
\hline Total benefits $\$ 000$ & 13,945 & \multicolumn{2}{|c|}{1,124} & & & \\
\hline \multicolumn{7}{|l|}{ COSTS $\$ 000$} \\
\hline Investment & $(52,768)$ & \multicolumn{2}{|c|}{$(4,254)$} & & & \\
\hline Operating & $(71,839)$ & \multicolumn{2}{|c|}{$(5,789)$} & & & \\
\hline Total & $(124,625)$ & \multicolumn{2}{|c|}{$(10,043)$} & & & \\
\hline NET BENEFIT & $(110,680)$ & \multicolumn{2}{|c|}{$(8,919)$} & & & \\
\hline B/C RATIO & $7 \%$ (base & \multicolumn{2}{|c|}{$3 \%$} & & & \\
\hline$\$ 17 /$ hour (base case) & 0.11 & \multicolumn{2}{|c|}{0.13} & & & \\
\hline$\$ 34 /$ hour & 0.22 & \multicolumn{2}{|c|}{0.26} & & & \\
\hline$\$ 70 /$ hour & 0.46 & \multicolumn{2}{|c|}{0.55} & & & \\
\hline
\end{tabular}


Table A-4: GA I-85 (Base)

\begin{tabular}{|c|c|c|c|c|c|c|}
\hline TRAFFIC IN PEAK & \multicolumn{3}{|c|}{ General purpose lanes } & \multicolumn{3}{|c|}{ Managed lanes } \\
\hline & Before & After & Change & Before & After & Change \\
\hline Vehicles/day in peak & 71,496 & 68,802 & $(2,694)$ & 9,429 & 8,608 & $(821)$ \\
\hline Time, minutes/vehicle & 16.1 & 17.4 & 1.3 & 14.2 & 13.8 & $(0.4)$ \\
\hline BENEFITS & General & Managed & Total & & & \\
\hline Minutes saved/day & $(95,029)$ & 15,866 & $(79,163)$ & & & \\
\hline \multirow[t]{2}{*}{ Time saved $\$ 000 / \mathrm{yr}$} & $(6,731)$ & 1,124 & $(5,607)$ & & & \\
\hline & \multicolumn{2}{|c|}{ Present value } & Typical year & & & \\
\hline Total benefits $\$ 000$ & $(69,582)$ & \multicolumn{2}{|c|}{$(5,607)$} & & & \\
\hline \multicolumn{7}{|l|}{ COSTS $\$ 000$} \\
\hline Investment & $(52,768)$ & \multicolumn{2}{|c|}{$(4,254)$} & & & \\
\hline Operating & $(71,839)$ & \multicolumn{2}{|c|}{$(5,789)$} & & & \\
\hline Total & $(124,625)$ & \multicolumn{2}{|c|}{$(10,043)$} & & & \\
\hline NET BENEFIT & $(194,207)$ & \multicolumn{2}{|c|}{$(15,650)$} & & & \\
\hline B/C RATIO & \multicolumn{2}{|c|}{$7 \%$ (base case) } & $3 \%$ & & & \\
\hline$\$ 17 /$ hour (base case) & \multicolumn{2}{|l|}{-0.56} & -0.66 & & & \\
\hline \$34/hour & \multicolumn{2}{|l|}{-1.12} & -1.32 & & & \\
\hline$\$ 70 /$ hour & -2.30 & \multicolumn{2}{|c|}{$\begin{array}{l}-1.32 \\
-2.72\end{array}$} & & & \\
\hline
\end{tabular}

Table A-5: LBJ (Base, 40\% Cost)

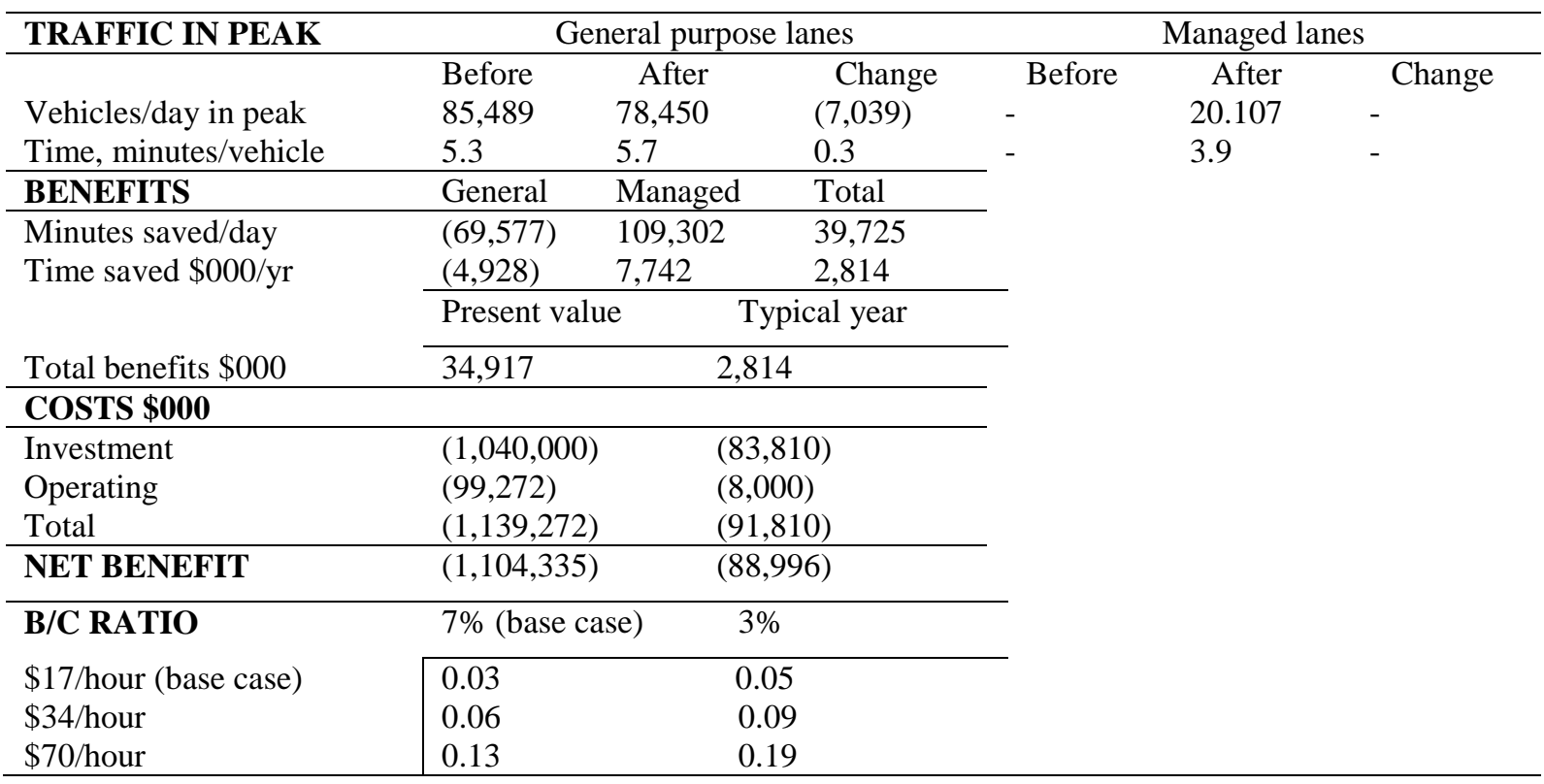

Table A-6: LBJ (Optimistic, 40\% Cost)

\begin{tabular}{|c|c|c|c|c|c|c|}
\hline \multirow[t]{2}{*}{ TRAFFIC IN PEAK } & \multicolumn{3}{|c|}{ General purpose lanes } & \multicolumn{3}{|c|}{ Managed lanes } \\
\hline & Before & After & Change & Before & After & Change \\
\hline Vehicles/day in peak & 85,489 & 78,450 & $(7,039)$ & - & 20.107 & - \\
\hline Time, minutes/vehicle & 5.3 & 5.7 & 0.3 & - & 3.9 & - \\
\hline BENEFITS & General & Managed & Total & & & \\
\hline Minutes saved/day & - & 109,302 & 109,302 & & & \\
\hline \multirow[t]{2}{*}{ Time saved $\$ 000 / y r$} & - & 7,742 & 7,742 & & & \\
\hline & \multicolumn{2}{|c|}{ Present value } & Typical year & & & \\
\hline \multirow{2}{*}{$\begin{array}{l}\text { Total benefits } \$ 000 \\
\text { COSTS } \$ 000\end{array}$} & 96,074 & \multicolumn{2}{|c|}{7,742} & & & \\
\hline & \multicolumn{3}{|c|}{ COSTS \$000 } & & & \\
\hline Investment & $(1,040,0$ & & & & & \\
\hline Operating & $(99,272)$ & & & & & \\
\hline
\end{tabular}




\begin{tabular}{llc} 
Total & $(1,139,272)$ & $(91,810)$ \\
\hline NET BENEFIT & $(1,043,199)$ & $(84,068)$ \\
\hline B/C RATIO & $7 \%$ (base case) & $3 \%$ \\
\$17/hour (base case) & 0.08 & 0.13 \\
\$34/hour & 0.17 & 0.25 \\
\$70/hour & 0.35 & 0.52 \\
\hline
\end{tabular}

Table A-7: LBJ (Base, 100\% Cost)

\begin{tabular}{|c|c|c|c|c|c|c|}
\hline \multirow[t]{2}{*}{ TRAFFIC IN PEAK } & \multicolumn{3}{|c|}{ General purpose lanes } & \multicolumn{3}{|c|}{ Managed lanes } \\
\hline & Before & After & Change & Before & After & Change \\
\hline Vehicles/day in peak & 85,489 & 78,450 & $(7,039)$ & - & 20.107 & - \\
\hline Time, minutes/vehicle & 5.3 & 5.7 & 0.3 & - & 3.9 & - \\
\hline BENEFITS & General & Managed & Total & & & \\
\hline Minutes saved/day & $(69,577)$ & 109,302 & 39,725 & & & \\
\hline \multirow{2}{*}{ Time saved $\$ 000 / y r$} & $(4,928)$ & 7,742 & 2,814 & & & \\
\hline & \multicolumn{2}{|c|}{ Present value } & Typical year & & & \\
\hline Total benefits $\$ 000$ & 34,917 & \multicolumn{2}{|c|}{2,814} & & & \\
\hline \multicolumn{7}{|l|}{ COSTS $\$ 000$} \\
\hline Investment & \multicolumn{2}{|c|}{$(2,600,000)$} & $(209,525)$ & & & \\
\hline Operating & \multicolumn{2}{|c|}{$(248,181)$} & $(20,000)$ & & & \\
\hline Total & \multicolumn{2}{|c|}{$(2,848,181)$} & $(229,525)$ & & & \\
\hline NET BENEFIT & \multicolumn{2}{|c|}{$(2,813,264)$} & $(226,711)$ & & & \\
\hline B/C RATIO & \multicolumn{2}{|c|}{$7 \%$ (base case) } & $3 \%$ & & & \\
\hline$\$ 17 /$ hour (base case) & \multicolumn{2}{|l|}{0.01} & 0.02 & & & \\
\hline$\$ 34 /$ hour & & 0.04 & & & \\
\hline$\$ 70 /$ hour & \multicolumn{2}{|l|}{$\begin{array}{l}0.02 \\
0.05\end{array}$} & 0.08 & & & \\
\hline
\end{tabular}

Table A-8: LBJ (Optimistic, 100\% Cost)

\begin{tabular}{|c|c|c|c|c|c|c|}
\hline \multirow[t]{2}{*}{ TRAFFIC IN PEAK } & \multicolumn{3}{|c|}{ General purpose lanes } & \multicolumn{3}{|c|}{ Managed lanes } \\
\hline & Before & After & Change & Before & After & Change \\
\hline Vehicles/day in peak & 85,489 & 78,450 & $(7,039)$ & - & 20.107 & - \\
\hline Time, minutes/vehicle & 5.3 & 5.7 & 0.3 & - & 3.9 & - \\
\hline BENEFITS & General & Managed & Total & & & \\
\hline Minutes saved/day & - & 109,302 & 109,302 & & & \\
\hline \multirow{2}{*}{ Time saved $\$ 000 / \mathrm{yr}$} & - & 7,742 & 7,742 & & & \\
\hline & \multicolumn{2}{|c|}{ Present value } & Typical year & & & \\
\hline Total benefits $\$ 000$ & 96,074 & \multicolumn{2}{|c|}{7,742} & & & \\
\hline \multicolumn{7}{|l|}{ COSTS $\$ 000$} \\
\hline Investment & \multicolumn{2}{|c|}{$(2,600,000)$} & $(209,525)$ & & & \\
\hline Operating & \multicolumn{2}{|c|}{$(248,181)$} & $(20,000)$ & & & \\
\hline Total & \multicolumn{2}{|c|}{$(2,848,181)$} & $(229,525)$ & & & \\
\hline NET BENEFIT & \multicolumn{2}{|c|}{$(2,752,107)$} & $(221,782)$ & & & \\
\hline B/C RATIO & \multicolumn{2}{|c|}{$7 \%$ (base case) } & $3 \%$ & & & \\
\hline$\$ 17 /$ hour (base case) & \multicolumn{2}{|l|}{0.03} & 0.05 & & & \\
\hline$\$ 34 /$ hour & \multicolumn{2}{|l|}{0.07} & 0.10 & & & \\
\hline$\$ 70 /$ hour & 0.14 & \multicolumn{2}{|c|}{0.21} & & & \\
\hline
\end{tabular}

Table A-9: NTE (Base, 40\% Cost)

\begin{tabular}{lllllcr}
\hline TRAFFIC IN PEAK & \multicolumn{3}{c}{ General purpose lanes } & \multicolumn{2}{c}{ Managed lanes } \\
\hline & Before & After & Change & Before & After & Change \\
Vehicles/day in peak & 48,305 & 57,807 & 9,502 & - & 16,762 & - \\
Time, minutes/vehicle & 8.2 & 6.8 & $(1.4)$ & - & 5.4 & - \\
\cline { 1 - 4 } BENEFITS & General & Managed & Total & & &
\end{tabular}




\begin{tabular}{|c|c|c|c|}
\hline \multirow{3}{*}{$\begin{array}{l}\text { Minutes saved/day } \\
\text { Time saved } \$ 000 / y r\end{array}$} & 156,701 & 99,744 & 256,446 \\
\hline & 11,100 & 7,065 & 18,165 \\
\hline & \multicolumn{2}{|c|}{ Present value } & Typical year \\
\hline Total benefits $\$ 000$ & 225,409 & & 18,165 \\
\hline \multicolumn{4}{|l|}{ COSTS $\$ 000$} \\
\hline Investment & $(840,000)$ & & $(67,693)$ \\
\hline Operating & $(99,272)$ & & $(8,000)$ \\
\hline Total & $(939,272)$ & & $(75,693)$ \\
\hline NET BENEFIT & $(713,863)$ & & $(57,528)$ \\
\hline B/C RATIO & $7 \%$ (base & ase) & $3 \%$ \\
\hline$\$ 17 /$ hour (base case) & 0.24 & & 0.36 \\
\hline$\$ 34 /$ hour & 0.48 & & 0.71 \\
\hline$\$ 70 /$ hour & 0.99 & & 1.47 \\
\hline
\end{tabular}

Table A-10: NTE (Base, 100\% Cost)

\begin{tabular}{|c|c|c|c|c|c|c|}
\hline \multirow{2}{*}{ TRAFFIC IN PEAK } & \multicolumn{3}{|c|}{ General purpose lanes } & \multicolumn{3}{|c|}{ Managed lanes } \\
\hline & Before & After & Change & Before & After & Change \\
\hline Vehicles/day in peak & 48,305 & 57,807 & 9,502 & - & 16,762 & - \\
\hline Time, minutes/vehicle & 8.2 & 6.8 & $(1.4)$ & - & 5.4 & - \\
\hline BENEFITS & General & Managed & Total & & & \\
\hline Minutes saved/day & 156,701 & 99,744 & 256,446 & & & \\
\hline \multirow[t]{2}{*}{ Time saved $\$ 000 / y r$} & 11,100 & 7,065 & 18,165 & & & \\
\hline & \multicolumn{2}{|c|}{ Present value } & Typical year & & & \\
\hline Total benefits $\$ 000$ & 225,409 & \multicolumn{2}{|c|}{18,165} & & & \\
\hline \multicolumn{7}{|l|}{ COSTS \$000 } \\
\hline Investment & \multicolumn{2}{|c|}{$(2,100,000)$} & $(169,231)$ & & & \\
\hline Operating & \multicolumn{2}{|c|}{$(248,181)$} & $(20,000)$ & & & \\
\hline Total & \multicolumn{2}{|c|}{$(2,348,181)$} & $(189,231)$ & & & \\
\hline NET BENEFIT & \multicolumn{2}{|c|}{$(2,122,772)$} & $(171,067)$ & & & \\
\hline B/C RATIO & \multicolumn{2}{|c|}{$7 \%$ (base case) } & $3 \%$ & & & \\
\hline$\$ 17 /$ hour (base case) & \multicolumn{2}{|l|}{0.10} & 0.14 & & & \\
\hline$\$ 34 /$ hour & \multicolumn{2}{|l|}{0.19} & 0.29 & & & \\
\hline$\$ 70 /$ hour & \multicolumn{3}{|l|}{0.40} & & & \\
\hline
\end{tabular}

Table A-11: WA I-405

\begin{tabular}{|c|c|c|c|c|c|c|}
\hline \multirow[t]{2}{*}{ TRAFFIC IN PEAK } & \multicolumn{3}{|c|}{ General purpose lanes } & \multicolumn{3}{|c|}{ Managed lanes } \\
\hline & Before & After & Change & Before & After & Change \\
\hline Vehicles/day in peak & 50,715 & 51,671 & 956 & 11,354 & 14,422 & 3,068 \\
\hline Time, minutes/vehicle & 24.2 & 21.9 & $(2.3)$ & 19.0 & 15.9 & $(3.1)$ \\
\hline BENEFITS & General & Managed & Total & & & \\
\hline Minutes saved/day & 109,060 & 106,303 & 215,363 & & & \\
\hline \multirow[t]{2}{*}{ Time saved $\$ 000 / y r$} & 7,725 & 7,530 & 15,255 & & & \\
\hline & \multicolumn{2}{|c|}{ Present value } & Typical year & & & \\
\hline Total benefits $\$ 000$ & 189,289 & \multicolumn{2}{|c|}{15,255} & & & \\
\hline \multicolumn{7}{|l|}{ COSTS \$000 } \\
\hline Investment & $(155,500)$ & \multicolumn{2}{|c|}{$(12,531)$} & & & \\
\hline Operating & $(490,778)$ & \multicolumn{2}{|c|}{$(39,550)$} & & & \\
\hline Total & $(646,278)$ & \multicolumn{2}{|c|}{$(52,081)$} & & & \\
\hline NET BENEFIT & $(456,979)$ & \multicolumn{2}{|c|}{$(36,826)$} & & & \\
\hline B/C RATIO & \multicolumn{2}{|c|}{$7 \%$ (base case) } & $3 \%$ & & & \\
\hline$\$ 17 /$ hour (base case) & 0.29 & \multicolumn{2}{|c|}{0.32} & & & \\
\hline$\$ 34 /$ hour & 0.59 & \multicolumn{2}{|c|}{0.64} & & & \\
\hline$\$ 70 /$ hour & 1.21 & \multicolumn{2}{|c|}{1.32} & & & \\
\hline
\end{tabular}


Table A-12: CA I-680 SB

\begin{tabular}{|c|c|c|c|c|c|c|}
\hline \multirow[t]{2}{*}{ TRAFFIC IN PEAK } & \multicolumn{3}{|c|}{ General purpose lanes } & \multicolumn{3}{|c|}{ Managed lanes } \\
\hline & Before & After & Change & Before & After & Change \\
\hline Vehicles/day in peak & 21,316 & 22,911 & 1,595 & 3,095 & 3192 & 98 \\
\hline Time, minutes/vehicle & 13.5 & 12.6 & $(0.9)$ & 11.5 & 11.2 & $(0.3)$ \\
\hline BENEFITS & General & Managed & Total & & & \\
\hline Minutes saved/day & 20,908 & 3,806 & 24,714 & & & \\
\hline \multirow[t]{2}{*}{ Time saved $\$ 000 / y r$} & 1,481 & 270 & 1,751 & & & \\
\hline & \multicolumn{2}{|c|}{ Present value } & Typical year & & & \\
\hline Total benefits $\$ 000$ & 21,723 & 1,7 & & & & \\
\hline \multicolumn{7}{|l|}{ COSTS \$000 } \\
\hline Investment & $(36,634)$ & \multicolumn{2}{|c|}{$(2,952)$} & & & \\
\hline Operating & $(55,841)$ & \multicolumn{2}{|c|}{$(4,500)$} & & & \\
\hline Total & $(92,475)$ & \multicolumn{2}{|c|}{$(7,452$} & & & \\
\hline NET BENEFIT & $(70,752)$ & \multicolumn{2}{|c|}{$(5,702)$} & & & \\
\hline B/C RATIO & \multicolumn{2}{|c|}{$7 \%$ (base case) } & $3 \%$ & & & \\
\hline$\$ 17 /$ hour (base case) & \multicolumn{2}{|l|}{0.23} & 0.27 & & & \\
\hline$\$ 34 /$ hour & \multicolumn{2}{|l|}{0.47} & & & & \\
\hline$\$ 70 /$ hour & 0.97 & \multicolumn{2}{|c|}{$\begin{array}{l}0.55 \\
1.13\end{array}$} & & & \\
\hline
\end{tabular}

Table A-13: FL I-95

\begin{tabular}{|c|c|c|c|c|c|c|}
\hline TRAFFIC IN PEAK & \multicolumn{3}{|c|}{ General purpose lanes } & \multicolumn{3}{|c|}{ Managed lanes } \\
\hline & Before & After & Change & Before & After & Change \\
\hline Vehicles/day in peak & 67,417 & 71,316 & 3,899 & 19,741 & 25,926 & 6,997 \\
\hline Time, minutes/vehicle & 17.1 & 8.3 & $(8.8)$ & 14.5 & 7.0 & $(7.5)$ \\
\hline BENEFITS & General & Managed & Total & & & \\
\hline Minutes saved/day & 576,544 & 257,461 & 834,005 & & & \\
\hline \multirow[t]{2}{*}{ Time saved $\$ 000 / \mathrm{yr}$} & 40,838 & 18,237 & 59,075 & & & \\
\hline & \multicolumn{2}{|c|}{ Present value } & Typical year & & & \\
\hline Total benefits $\$ 000$ & 733,069 & \multicolumn{2}{|c|}{59,075} & & & \\
\hline \multicolumn{7}{|l|}{ COSTS $\$ 000$} \\
\hline Investment & $(132,000)$ & \multicolumn{2}{|c|}{$(10,637)$} & & & \\
\hline Operating & $(53,052)$ & \multicolumn{2}{|c|}{$(4,275)$} & & & \\
\hline Total & $(185,052)$ & \multicolumn{2}{|c|}{$(14,912)$} & & & \\
\hline NET BENEFIT & 548,017 & \multicolumn{2}{|c|}{44,163} & & & \\
\hline B/C RATIO & $7 \%$ (base & \multicolumn{2}{|c|}{$3 \%$} & & & \\
\hline$\$ 17 /$ hour (base case) & 3.96 & \multicolumn{2}{|c|}{5.37} & & & \\
\hline$\$ 34 /$ hour & 7.92 & \multicolumn{2}{|c|}{10.73} & & & \\
\hline$\$ 70 /$ hour & 16.31 & \multicolumn{2}{|c|}{22.09} & & & \\
\hline
\end{tabular}

